\title{
Effective Shear Connection for Shallow Cellular Composite Floor Beams
}

\author{
Toi Limazie ${ }^{1,2}$, Shiming Chen ${ }^{1} *$ \\ ${ }^{1}$ School of Civil Engineering, Tongji University, Shanghai 200092, China \\ 2 JZFZ Architectural Design Co.Ltd, Chengdu, 610021, China \\ *Corresponding author: Tel.: +86 21 65986183; fax: +86 2165982668 \\ E-mail address: chensm@tongji.edu.cn
}

\begin{abstract}
Shallow cellular Composite Floor Beam is a new type of composite floor beam that usually consists of a structural steel beam with regularly spaced web openings and concrete slab casted above the steel decking. In this study, the shear transferring mechanisms of shallow cellular composite beams design with innovative shear connection systems are investigated. A detailed finite element analysis program was performed to investigate the force transferring mechanism, load bearing capacity and failure behavior of the shear connections under direct longitudinal shear forces by simulating the push-out tests. Four different configurations of shear connections (web opening configurations) were designed and an intensive parametric study was conducted to determine the material and geometric parameters that likely influence the behavior of the shear connection. Finally, the findings from this investigation are incorporated with the bending and push-out test results to develop design methods for this form of shear connection. The failure mechanisms of the shear connection were confirmed, and it was also revealed that this type of shear connection is effectively


capable to provide the desired shear resistance and ductile behavior if designed properly.

Keywords: Finite element modeling; shear transfer; contact modeling; tie-bar element; infill concrete; web opening.

\section{Introduction}

The increasing demand of long span beams and shallow floor depth had led to the development of various slim floor systems such as Slimflor, Slimdek, Asymmetric Slimflor Beam (ASB) and Ultra Shallow Floor Beam, being used in commercial and residential buildings, hospitals, schools, etc.... The slim floor system usually is composed of profiled steel decking, an embedded steel beam and the concrete slab, resulting in a flat appearance of the floor (Fig. 1) and it offers important benefits in terms of features such as long spanning without or with fewer secondary beams, shallow floor depth, inherent fire resistance, etc... (Lawson et al. [1-3], Hicks et al. [4]), as well as others advantages offered by the conventional composite beams. The use of composite slim floor systems requires comprehension of the behavior of all structural components, among which the shear transfer between the steel beam and concrete slab that enables a composite action is one important aspect in design of the composite slim floor systems.

The composite slim floor systems have been studied in terms of the integrated composite beam (Lawson et al. [1-2]; Mullet et al. [5-7]; Wang et al. [8]) and several experimental studies were conducted in the last decades. However, the roles that shear connections and shear transfer mechanism play in the overall behavior of the composite slim floor system are not yet well understood. In ordinary slim floor beams such as Slimfloor, Slimdek and ASB, the shear transfer is only assumed 
providing by the bonding effect at the interface between the concrete and steel beam. This adhesion based bond strength is found very limited and is prone to shear failure under small load. To enable a ductile behavior, it is essential to increase and assure an effective interaction between the two elements. Therefore, an enhanced form of slim floor beam called the shallow cellular composite floor beam which consists of a row of regularly spaced web openings perforated in the encased steel web was proposed. Shallow Cellular Composite Floor Beam (SCCFB) is a generic term used for this type of composite floor construction where the key feature is that the steel beam with regularly spaced web openings is contained within the concrete slab.

Two configurations of the shear connection are designed representing different web opening geometries: the "circular opening" and the "clothoidal opening". A series of push-out tests on the circular opening shear connection configuration were performed by Huo and D'Mello [9], while the circular and clothoidal openings shear connections configurations were also investigated through a series of flexural bending tests by Chen et al. [10]. Based on these previous investigations, an explicit finite element analysis was conducted to study the distinct behavior of the shear connection, and four different web opening configurations were designed and investigated by simulating the push-out test. The experimental and FE simulations results were all analyzed in terms of the load bearing capacity, failure behavior and longitudinal force transfer mechanism of the shear connections. It aims to develop the design procedure for the longitudinal shear resisting capacity of the shear connection configuration.

\section{The innovative shear connection system}

\subsection{Structural configuration}


Shear connection in steel-concrete composite construction is defined as an interconnecting element set between the steel and concrete of a composite structural member. To enable effective composite action, the shear connection should have sufficient strength and stiffness. In this study, the shear connection is formed by combining the cast-in-place concrete (the infill concrete element) passing through the openings with a reinforcing bar (tie-bar element). The generic form of the shear connection system is depicted in Fig. 2. Two configurations of the shear connections

are designed representing different web opening geometries namely the "circular opening" shear connection and the "clothoidal opening" shear connection. The circular opening shear connection is set for an "asymmetric I section" steel beam, while the clothoidal opening shear connection is set for an "inverted T section" steel beam. The schematic configuration of the two shear connections is shown in Fig. 3.

\subsection{Shear transfer mechanism}

Different from the conventional shear connections in down-stand composite beams, in this SCCFB shear connection, the concrete completely fills the steel web openings and the force flow interacts between the steel web and the infill concrete. As the steel element is embedded within the concrete, the major part of the shear connection is activated by a combination of the infill concrete and the steel tie-bars. The shear bond at the interface between the steel beam and the concrete slab also contributes to the shear transfer mechanism within the SCCFB. The force transfer between different components and the mechanism of the composite action can be interpreted as: at the initial loading, the adhesion, the friction and the local compression are all activated at the contact zone of the connection system. The encased steel beam is subject to a longitudinal shear inducing bending and shear stresses in the section. With the load 
increasing, the shear resistance capacity of the concrete element passing through the opening will be reached, and large amount of slip would occur at the interface between the steel beam and the concrete slab, accompanying with initiation of cracks within the infill concrete. At this stage, the reinforcing tie-bars embedded in the infill concrete will contribute to improve the post-cracking behavior of the shear connection. As the load continues increasing meanwhile the concrete crushing continues, the tensile forces provided by the tie-bar elements will penetrate the cracks and increase the bearing capacity of the shear connection. When the load further continues increasing, cracks will also spread out in the infill concrete as well as in the concrete slab and redistribution of the internal forces will occur among the steel section member, the confined concrete and the steel reinforcing tie-bar (Fig. 4). To enable the desired bearing capacity and the ductile behavior of the shear connection, the presence of the tie-bar element would be very critical, and it enables the infill concrete element to carry the resulting tensile forces within the shear connection. Without the tie-bar elements, the shear connection would exhibit a brittle failure. Compared to headed shear studs, this type of shear connection is also an integral part of the composite beam, and it results in a complex superposition of the internal forces and shear bond stress in the system.

\section{Finite element modeling}

\subsection{Geometric modeling}

The finite element analysis study presented herein is based on the push-out test presented by Huo and D'Mello [9] and the bending test presented by Chen et al. [10]. The purpose is to develop accurate and reliable FE models in simulation of the pushout performance of the "concrete plug with tie-bar" shear connection in a composite slim floor beam. The FE models were established using ANSYS, considering all 
aspects that would likely influence the accuracy of the investigation (material properties; appropriate selection of element type and mesh size; appropriate set of boundary conditions and load; rational setting of analysis procedures; etc.). The generated FE models were first validated against the reference test results. The pushout test specimens [9] all consist of a steel section element and a concrete slab. The steel section element is a short universal column $(254 \times 254 \times 73 \mathrm{UC})$ with three circular opening of $150 \mathrm{~mm}$ in diameter, spacing at $75 \mathrm{~mm}$ as shown in Fig. 5 . The width of the concrete slab is $1000 \mathrm{~mm}$ and the two parts of the concrete slab on both sides of the steel section are connected by the infill concrete passing through the openings.

As the specimen has symmetric planes, only a half of the specimen is numerically modeled in this study with appropriate symmetry boundary conditions. Also, to save the computing time and cost, only one shear connection (one opening) is modeled, rather than three web openings as in the push-out test.

The steel section is modeled using element Solid95, which is a solid element defined with 20 nodes and three degrees of freedom at each node, as illustrated in Fig. 6(a). The Solid95 is capable of modeling the plasticity, creep, stress stiffening, large deformation and large strain. The concrete slab and the infill concrete are modeled using the Solid65 element which has the capability of accurately modeling cracking in tension and crushing in compression of concrete. Fig. 6(b) shows the schematic illustration of the Solid65 element.

To capture the stress distribution over the loading process, the models were minutely meshed using the designated mesh tool with controlled element size. The infill concrete within the opening was meshed using element size of $15 \mathrm{~mm}$. Similarly, the steel beam section was meshed using the size of $15 \mathrm{~mm}$. The concrete slab was divided into two parts and meshed in different element size. The concrete part close to 
the shear connection (the concrete within the steel flanges) was meshed using element size of $30 \mathrm{~mm}$, while the concrete far from the shear connection was meshed in a size of $40 \mathrm{~mm}$. The meshed model of the push-out test is shown in Fig. 7.

\subsection{Material properties}

Material properties of concrete and steel members obtained from the material tests given in Table 1 were used in the FE analysis. The material nonlinearity for the concrete element was described by the stress-strain relationship, considered as an isotropic material and defined together with the failure surface model define by the FE program. The stress and strain relationship determined in accordance with the Chinese Code for Concrete Design (GB50010-2010) [11] is used for concrete, expressed in Eqs. (1) and (2). The concrete reaches its maximum compressive stress at the strain value of 0.002 , and beyond the peak stress $\left(f_{c}\right)$, the concrete strain would reach the maximum value of 0.0033 .

$$
\begin{array}{ll}
\text { For } \varepsilon_{\mathrm{c}} \leq \varepsilon_{0}: & \sigma_{c}=f_{c}\left[1-\left(1-\frac{\varepsilon_{c}}{\varepsilon_{0}}\right)^{n}\right] \\
\text { For } \varepsilon_{0}<\varepsilon_{\mathrm{c}} \leq \varepsilon_{\mathrm{cu}}: & \sigma_{c}=f_{c}\left[1-0.15\left(\frac{\varepsilon_{c}-\varepsilon_{0}}{\varepsilon_{c u}-\varepsilon_{0}}\right)\right]
\end{array}
$$

The von Mises yield criterion of isotropic hardening is implemented for the structural steel section. The strain-stress curve is assigned in the FE models by specifying the yield strength, the ultimate strength and the elastic modulus. The material nonlinearity of the model is incorporated in the program by the multi-linear strain-stress curve as illustrated in Fig. 8.

The uniaxial concrete tensile strength $\left(f_{t}\right)$ and the uniaxial concrete compressive strength $\left(f_{c}\right)$ are used to define the failure criteria of the concrete, especially cracking 
and crushing pattern in concrete. The input of the crack opening and shear transfer coefficient $\left(\beta_{t}=0.25\right.$ and $\left.\beta_{c}=0.75\right)$ are used during the simulations, which enable some shear transfer for the concrete material model.

\subsection{Contact modeling}

The contact elements are used to model the interaction between the steel and concrete elements. The surface-to-surface contact was used and the contact problem was considered as a rigid-to-flexible contact problem. The steel beam surfaces in contact with the concrete slab are chosen as target surface and modeled using the TARGE170 element, while the concrete surfaces are set as the contact surface and modeled using the CONTA174 element. Since contact modeling is highly nonlinear and very complex and very likely to lead to a convergence failure and to an early termination of the computation process, it is important to define correct contact parameters, such as the initial contact conditions, the penetration tolerance, the contact stiffness, etc. To ensure the correct initial contact, all the initial penetrations were excluded in the contact model, in such a way that the contact pairs are only in contact in the initial geometry, i.e. the two contact elements are "just in touch".

The penetration tolerance was used in conjunction with the augmented Lagrangian method, which is the default contact algorithm for surface-to-surface contact problem. The penetration tolerance is a factor used to specify an allowable maximum penetration, and should be defined carefully since if any penetration larger than the defined value is detected during the computation, the analysis solution would fail in convergence even if the displacements and forces are all within the convergence criteria. The contact stiffness defines the amount of penetrations between the two surfaces in contact. Based on the material properties of the deformable element, the 
ANSYS program can automatically estimate a default value for the contact stiffness. If the contact stiffness factor is underestimated, global convergence difficulties might be caused by too much penetration rather than by residual forces. If it is overestimated, global convergence might require many equilibrium iterations for achieving convergence tolerance rather than penetration. The default values for the penetration tolerance $(\mathrm{FTOLN}=0.1)$ and that of the contact stiffness $(\mathrm{FKN}=0.01)$ caused an excessive number of iterations and non-convergence at relatively small slips. Finally, the optimum inputs of FTOLN $=1.0$ and FKN $=0.08$ were achieved for the FE calibrations, and good agreements in the slips and in the ultimate loads between the FE and the test results were achieved.

\subsection{Boundary conditions and loading}

Due to the symmetry of the specimen, only one half was modeled with appropriate boundary conditions. All nodes on the cutting plane of the steel beam section and the infill concrete within the opening are restricted in the global $\mathrm{Z}$ direction to model the specimen symmetry. For the support boundaries, the specimen is rigidly fixed at the base. Therefore, the FE model restrains all degrees of freedom at the base (support) of concrete slab.

The displacement is applied as load on the top part of the steel section in the FE modeling. The total amount of displacement is divided into a number of sub-steps to simulate the incremental load applied in the push-out test, and the automatic time stepping is activated to ensure that the optimum load increment is used when the nonlinear behavior occurs. The Newton-Raphson equilibrium iteration is adopted to provide convergence at the end of each load increment within the tolerance limits.

\section{Finite element analysis calibration}


The finite element models developed for the push-out test simulations are calibrated against the reference push-out test results reported by Huo and D'Mello [9]. The test group $\mathrm{T} 5$ is used for the validation and the same material strengths as those summarized in Table 1 are used. The axial load versus vertical displacement (slip) curves obtained from the push out tests and the finite element simulations are compared in Fig.9. The ultimate loads $\left(P_{F E A}\right)$, the slip $\left(\delta_{F E A}\right)$ predicted from the FE simulation are compared with the experimental results, as illustrated in Table 2. The simulation results are found in good agreement with the test results. The maximum percentages of differences between the test and the FE simulation results for the ultimate loads are $1.5 \%$ and $5.4 \%$ for specimens T5-1 and T5-3, respectively, while the differences in the maximum slips are $1.2 \%$ and $0.3 \%$, respectively. The slip stiffness, the ultimate loads and slips obtained from the numerical simulations are very close to those obtained from the push-out tests.

Identical failure mechanisms are also observed in the numerical simulations, where the brittle failure mode of the shear connection (infill concrete element) was shown. Figs. 10(a) to 10(d) illustrate the stress contour plots derived from the finite element analysis for the T5-1 model $\left(f_{c}=35 \mathrm{~N} / \mathrm{mm}^{2}\right)$, including the von Mises stress plots and the stress plots in the three different directions, for both concrete slab and steel beam section. These plots clearly illustrate the compression and tension zones within the shear connection, i.e. the infill concrete element, under a longitudinal shear force. It is also observed that the upper part of the infill concrete is in a compression region. The infill concrete element is finally crushed since the concrete in the upper region of the shear connection reaches the ultimate compressive strength. The tensile splitting region is also clearly identified in the stress contour plots. Similar to the test findings, 
the infill concrete element fails far before yield occurrence in the steel beam section in the FE simulation.

As observed in the push-out tests, the numerical simulations of the shear connection specimens also reveal that the upper part of concrete is crushed by the steel web post in a relative deformation induced by the longitudinal shear force, while the rest of the infill concrete fails in tensile splitting. The calibrations showed good agreements between the push-out tests and the finite element analysis in terms of the ultimate loads, slips, stress distribution and failure patterns. It is then concluded that the FE models are reliable and accurate for predicting the structural behavior of the shear connection with the same effectiveness as the experimental study.

\section{Structural behavior of the shear connection}

The verified models are used in the parametric study of the shear connection. Geometric and material parameters involved in the FE investigation are the material strength (concrete and steel) and the geometric characteristics (opening shape, opening size, steel dowel shape, steel web thickness, tie-bar size, etc.).

Two configurations of "concrete plug with tie-bar" shear connection, i.e. the "circular opening shear connection" and the "clothoidal opening shear connection" are involved in the study. Three build-up clothoidal shapes are designed and included in the FE study. The concrete strength is varied from $25 \mathrm{~N} / \mathrm{mm}^{2}$ to $50 \mathrm{~N} / \mathrm{mm}^{2}$, while the steel yielding strength is varied from $300 \mathrm{~N} / \mathrm{mm}^{2}$ to $500 \mathrm{~N} / \mathrm{mm}^{2}$.

The push-out specimens are modeled with two parts, i.e. the structural steel beam and the concrete slab. The steel beam is modeled using an "inverted T section" steel beam with one opening perforated in the steel web, and the concrete slab of one meter in width. The geometrical configuration of the push out specimen is illustrated in Fig. 11. 


\subsection{Influence of the opening shape}

The influence of shear connection shape on the characteristic load bearing behavior, slip capacity and failure mechanisms have been analyzed. Fig. 12(a) illustrates the designed shear connections, labeled as "CO-O", "CL-C", "CL-CE", and "CL-Z"; according to their cutting shapes. The series labeled by "CO" refer to the shear connection with "circular openings" cutting and the series labeled by "CL" refer to the shear connection with "clothoidal openings" cutting. Both circular configuration and clothoidal cutting shear connections are designed with the same area of opening, i.e. the infill concrete element. The specimens are all designed with the infill concrete area of $14000 \mathrm{~mm}^{2}$. The dimensions of different steel sections used for the simulations are shown in Fig. 12(b). For the concrete, the uniaxial concrete compressive strength $\left(f_{c}\right)$ is taken equal to $30 \mathrm{~N} / \mathrm{mm}^{2}$; the uniaxial tensile strength $\left(f_{t}\right)$ taken is $2.1 \mathrm{~N} / \mathrm{mm}^{2}$ and the elastic modulus $\left(E_{c}\right)$ is $32000 \mathrm{~N} / \mathrm{mm}^{2}$. For the steel section, a nominal yielding strength of $420 \mathrm{~N} / \mathrm{mm}^{2}$ and the elastic modulus of $200 \mathrm{kN} / \mathrm{mm}^{2}$ are used. Comparisons are made between the different cutting shapes in terms of the load capacity $\left(P_{\max }\right)$ and the maximum slip $\left(\delta_{\max }\right)$ to investigate the effect of opening shape on the behavior of the shear connection, as shown in Fig. 13 and Table 3. In Table 3, the slip stiffness $(K)$ of the shear connection is defined as the secant linear stiffness of the load-slip curve, which is the ratio of the ultimate load and the slip at the ultimate load. It should be noted that for the four configurations, the computation was terminated due the damage of the shear connection (failure in concrete), which was solely composed by the infill concrete without the tie-bar element.

It appears that the shear connections with similar infill concrete area have almost the same slip stiffness, but vary in the efficiency of resisting longitudinal shear force. Specimens CO-O and CL-C possess higher load capacities, $189 \mathrm{kN}$ and $180 \mathrm{kN}$, 
respectively as compared to specimens CO-CE and CL-Z. But all the shear connections experienced the similar failure, and the concrete near the steel web was crushed by local compression induced by the relative deformation of the steel web post, and the rest of infill concrete failed in tensile splitting. The stresses contour plots in concrete and steel are shown in Fig. 14. The stress plots in Fig. 14 clearly demonstrates and confirms that the top part of the infill concrete is in compression. It can be also seen from these plots that the maximum compressive strength of the concrete $\left(f_{c}=30 \mathrm{~N} / \mathrm{mm}^{2}\right)$ was reached at the top part, but the maximum yielding strength of the steel section $\left(f_{y}=420 \mathrm{~N} / \mathrm{mm}^{2}\right)$ was not reached.

\subsection{Influence of the shear connection size}

The effect of shear connection size is investigated by modeling the shear connections with different opening sizes. Two opening configurations (CO-O and CL-C) are selected for the specific simulation. From the above investigations, it is evident that the loading behavior as well as the failure mechanism would be identical and therefore be replicable to other shear connection shape configuration. The infill concrete area is modeled with $14000 \mathrm{~mm}^{2}, 8400 \mathrm{~mm}^{2}$ and $4200 \mathrm{~mm}^{2}$ respectively, and the same material properties and geometric dimensions are adopted in the analysis.

The comparisons are illustrated graphically in Figs. 15(a) and 15(b), and numerically in Table 4. It reveals that the infill concrete element size significantly influences the load capacity of the shear connection, as it contributes to the local compression resistance and the tensile splitting resistance of the shear connection. The load and slip curve of the shear connection is almost linearly proportional to the size of the concrete infill. For the shear connection with the same concrete strength, the load capacity increases with the infill concrete area. The infill concrete size slightly 
influences the slip capacity, but a significant reduction in slip stiffness of the shear connection. Here again, the all the specimens failed due the crushing of the infill concrete element.

\subsection{Influence of the concrete strength}

The influence of concrete strength on the shear connection is investigated using CO-O and CL-C configurations, with an opening size of $14000 \mathrm{~mm}^{2}$. The compressive strength of concrete is taken as $25 \mathrm{MPa}, 30 \mathrm{MPa}, 40 \mathrm{MPa}$ and $50 \mathrm{MPa}$ respectively.

Figs. 16(a) and 16(b) illustrate the influence of concrete strength on the load-slip behavior of the shear connections with circular opening (CO-O) and clothoidal opening (CL-C), respectively. These plots demonstrate that the concrete characteristics have significant effects on the overall behavior of the shear connection. Increasing the compressive and tensile splitting strengths of the concrete can significantly improve the longitudinal shear resistance of the shear connection. Also, the slip capacity of the shear connection is found influencing by the concrete strength, as the slip capacity of all shear connections increases with the compressive strength of concrete. Generally, the longitudinal load resistance of both types of shear connection increases with the concrete strength. It can be remarked that the likely linear load-slip performance of the shear connections would be due to the fact that these shear connections were solely composed by the infill concrete passing through the web opening, and the computations were almost all terminated when damage of the concrete occurred. The failure patterns of the shear connection are also compared and it is observed that for relatively low and normal strength concrete (25 40MPa), the shear connection fails in local compression and splitting of the infill concrete without yielding in the steel beam, whereas for high strength concrete (50MPa), the shear 
connection fails in a mixed failure pattern of infill concrete crush and yielding in the steel web post.

\subsection{Influence of the steel beam strength}

The steel web post is an integrated part of the "concrete plug with tie-bar" shear connection. To investigate the influence of the web post strength, the CO-O and CL-C configurations are adopted and yield strength of the steel element is taken $300 \mathrm{MPa}$, 400MPa and 500MPa respectively. The concrete compressive strength and tensile strength are $30 \mathrm{~N} / \mathrm{mm}^{2}$ and $2.1 \mathrm{~N} / \mathrm{mm}^{2}$, respectively. The results show that increasing strength of the steel beam slightly affects the load resistance capacity and slip stiffness of the shear connections, as illustrated in Figs. 17(a) and 17(b). Although the steel strength has minor influences on the load resistance and slip stiffness of the shear connection, it is observed that the steel strength would influence the failure mode of the shear connection. The local action within the opening could induce significant stresses within the steel element, inducing premature failure in steel web post rather than failure in concrete element, especially for a thin web post and low steel strength. Yielding occurs in the steel web post for the shear connection designed with yield strength of 300MPa, in both circular and clothoidal configurations.

\subsection{Influence of the steel web post thickness}

The contact area between the steel web and the infill concrete directly contributes the local action of the shear connection system. The magnitude of this contact area could be critical for an effective longitudinal shear transferring mechanism. To evaluate this effect, the thickness of steel web was varied for $10 \mathrm{~mm}, 14 \mathrm{~mm}$ and $20 \mathrm{~mm}$ in both circular and clothoidal configurations. Steel yield strength of 400MPa and concrete 
compressive strength of $30 \mathrm{MPa}$ are adopted in the numerical simulation. The effect of varying the web thickness on the load and slip capacities is illustrated graphically in Figs. 18(a) and 18(b) for circular and clothoidal configurations, respectively. It is shown that the behavior of the shear connection is influenced by the thickness of the web post, as it was observed that both the slip and load resistance increase considerably with the thickness of the steel web. It reveals that an increase of more than $40 \%$ in the load capacity can be achieved when the thickness of the steel web post is doubled. Thicker web sections increase the local action of the shear connection by increasing the contact surface and thus increase the longitudinal shear transferring path, but also prevent excessive concentration of stress in the shear connection. Using thicker web section is also found likely enhancing the ductile behavior of the shear connection as shown in the load-slip curves (Fig.18).

\subsection{Influence of the reinforcing tie-bar element}

The behavior of the tie-bar element is investigated by incorporating a reinforcing bar within the infill concrete element passing through the opening center. The length of the reinforcing tie-bar element is the same as that of the concrete slab. The FE models are established considering various diameters of reinforcing tie-bar and two distinct infill concrete sizes to evaluate the contribution of the tie-bar on the shear connection behavior. In the numerical simulations, the tie-bar diameters are varied from $8 \mathrm{~mm}$ to $20 \mathrm{~mm}$, and the infill concrete element sizes are $4200 \mathrm{~mm}^{2}$ for circular opening (CO-O3) and $17000 \mathrm{~mm}^{2}$ for clothoidal opening (CL-C-1). The steel beam has $14 \mathrm{~mm}$ thick web post and a yield strength of $400 \mathrm{MPa}$, while the compressive strength of concrete is $30 \mathrm{MPa}$. 
The computational results are compared to the reference specimens which do not have the reinforcing tie-bar (CO-O-3 and CL-C-1), in terms of the ultimate load, slip stiffness and failure mechanism. The results are illustrated and compared in Table 5 and the load-slip behaviors are depicted in Figs. 19(a) and 19(b) for circular and clothoidal openings, respectively.

The combination of the reinforcing tie-bar with the infill concrete leads to significant changes in the load and slip behavior of the shear connection. The slips capacities of the shear connection at the ultimate load are significantly increased as compared to the reference specimens without tie-bar element. Better ductile behavior is observed in all the shear connection specimens with the tie-bar element. Increase of slip capacity is also demonstrated for the shear connection with additional reinforcing tiebar, but the initial slip stiffness of the two configurations (shear connection without and with tie-bar) is almost the same. This suggests that the slip stiffness of the "concrete plug with tie-bar" shear connections is independent on the tie-bar element. It should be noted that as it is specified in design codes (EN1994-1-1:2004) [12], the slip capacity of the shear connection should be taken as the slip at the load dropped at $10 \%$ below the ultimate load. For the present study, since the computations terminated before drop of the load reaches this limit, therefore, the slip capacity of the shear connection is taken as the slip at the end of the computation, while the slip stiffness of the shear connection is defined as the linear stiffness of the load-slip curve, which is the ratio of ultimate load and the slip at the ultimate load. Hence, the shear connection with tie-bar element has a significant increase in the slip capacity, being 1.6, 1.8, 2.1, 2.2, 2.2, and 2.3 times that of the shear connection without tie-bar element, for circular opening shear connections with $8,10,12,14,16$ and 20mm diameters tie-bar, respectively. For clothoidal connection with 12 and $16 \mathrm{~mm}$, the increase in the slip 
capacity is 1.5 and 1.6 times that of the reference shear connection, respectively. Consistence contributions in the longitudinal shear resistance capacity of the shear connections are also demonstrated in the numerical simulations. By comparing the two types of shear connection, i.e. without and with tie-bar element, it is addressed that the additional reinforcing tie-bar element considerably increases the longitudinal shear resisting capacity of the shear connection, as revealed in Table 5 and Fig. 19. For the shear connection of circular opening with $4200 \mathrm{~mm}^{2}$ area of the infill concrete element, and having $8,10,12,14,16$ and $20 \mathrm{~mm}$ diameters tie-bar respectively, the increase in the load capacity is $1.2,1.36,1.6,1.72,1.82$ and 1.93 times of the load capacity of the reference shear connection without tie-bar element. The increase in the longitudinal load capacity of the clothoidal shape shear connection with $17000 \mathrm{~mm}^{2}$ of infill concrete having 8,12 , and $16 \mathrm{~mm}$ tie-bar is $1.11,1.4$ and 1.65 , respectively. The presence of the tie-bar within the shear connection will also influence the failure mechanism of the shear connection. The combination of tie-bar and infill concrete enables the resistance of the shear connection to be sustained over the ultimate load state with significant ductile behavior. But the ultimate failure of the infill concrete element is almost similar to that without tie-bar element, where a part of the infill concrete is crushed under the local compression by the web post moving, while the rest is ruptured by tensile splitting. The brittle failure of the shear connection is no more observed for the shear connection combining tie-bar and infill concrete. The effect of the tie-bars on the structural behavior and shear strength of the shear connections were experimentally and numerically investigated and presented by Chen et al. [10] and Toi and Chen [14].

\section{Discussions}


From the observations gained from the experimental investigations (push-out and bending tests [9-10]) and the FE simulations, it is obvious that the shear transferring mechanisms of this new shear connection system are quite different to those of the conventional headed stud shear connections. The concrete plug shear connection fails due to the cracks and damage of the infill concrete element. An effective reinforcement (tie-bar element) embedded within the infill concrete can significantly enhance the ductile behavior beyond the ultimate capacity of the shear connection. Beyond the cracking loading, cracks formation spreads out in the infill concrete and redistribution of forces occurs from a confined compression to the tie-bar element in the concrete. The tie-bar also develops a well confined environment, increases its load bearing capacity due to the block action developed within the opening, since the progression of crack width can be prevented by the crossing tie-bar element. The longitudinal force introduces stress by local compression into the infill concrete element (uncracked) which is well reinforced by the tie-bar. As shown in Fig. 4, when loaded under local compression, spalling forces would be introduced into the shear connection, and if the infill concrete is reinforced adequately by the tie-bar element, the local composite action would be significantly increased. When the splitting tensile stress induced by the web post exceeds the tensile strength of the infill concrete, it causes cracks within the concrete and the tensile stresses are transferred within the tiebar element, while the concrete in front of the steel web post crushes with pulverized concrete, as it is well shown in flexural tests [10] and the push-out test [9]. These concrete pulverizations further increase the slips between the concrete and steel beam. However, based on the shear interfaces action with the slips, the action of the tie-bar element is globally mobilized and prevents the progression of shear forces within the shear connection. It is therefore obvious that the shear resisting behavior of the 
concrete plug with tie-bar type shear connection results in a perfect combination of the resistance of both the infill concrete element and the tie-bar element.

\section{A Tentative design method for the shear connection}

\subsection{Longitudinal shear resisting capacity}

Based on the failure mechanisms of the shear connection system observed from the experimental and FE investigations, it is concluded that the behavior of this type of shear connection is governed by three main elements which constitute the shear connection system (Fig. 3); and they are the infill concrete within the opening, the reinforcing tie-bar and the steel web post. The shear connection would fail due to the cracks and damage of the infill concrete element. Hence, an effective reinforcement (tie-bar element) embedded within the infill concrete can significantly enhance the ductile behavior beyond the ultimate capacity of the shear connection. The tie-bar also develops a well confined environment for the shear connection, and increases its load bearing capacity. At the ultimate loading, cracks formation spreads out in the infill concrete and a corresponding redistribution of forces occurs from a confined compression state into the tie-bar element in the concrete (Fig. 4). After the failure of the bonding adhesion, the bearing capacity of the shear connection is influenced by the pulverization of the local compression in the contact area between the infill concrete and the steel web post. As shown in Fig. 4, under local compression, spalling forces would be introduced into the shear connection, and if the infill concrete is reinforced adequately by the tie-bar element, the local compression would be significantly increased. When the splitting tensile stress induced by the web post exceeds the tensile strength of the infill concrete, it will cause cracks within the concrete and the resulted tensile stresses are transferred within the tie-bar element, 
while the concrete in front of the steel web post crushes with pulverized concrete. However, based on the shear interfaces action with the slips, the action of the tie-bar element is globally mobilized and prevents the progression of shear forces within the shear connection. Based on these mechanisms, it can be conclude that the shear resisting capacity of the "concrete plug with tie-bar" shear connection is provided by both the actions of the infill concrete and the tie-bar elements. Therefore, it is assumed that the shear resistant strength of the shear connection can be calculated by adding the concrete compressive capacity and the tensile strength provided by both the infill concrete and the reinforcement (tie-bar) embedded. The ultimate shear resistance of the shear connection is mathematically expressed by Eq.(3) as follows:

$$
R_{s h}=1.2\left(t_{w} h_{D} f_{c u}\right)+2.1 A_{c} f_{c t}\left(1+13.5 \frac{E_{s} A_{s t}}{E_{c} A_{c}}\right)
$$

Where: $A_{s t}=\frac{\pi D_{t b}^{2}}{4}$

$R_{s h}: \quad$ the shear resistance of an individual shear connection;

$A_{c}: \quad$ the cross-section area of infill concrete;

$A_{s t}: \quad$ the cross-section area of reinforcing tie-bars;

$D_{t b}: \quad$ the diameter of the tie-bar;

$t_{w}: \quad$ the thickness of the steel web post;

$h_{D}$ : the height of the web opening;

$f_{c u}: \quad$ the concrete cube compressive strength;

$f_{c t}$ : the concrete cube tensile splitting strength;

$E_{c}: \quad$ the elastic modulus of concrete;

$E_{s}: \quad$ the elastic modulus of steel element 
The first part of the equation represents the local compression capacity of the shear connection, while the second part represents the tensile splitting strength of the shear connection, combining the infill concrete and the tie-bar.

As mentioned previously, in the loading process, progression of cracks within the shear connection is prevented by the crossing tie-bar, and it increases the shear resisting mechanism of the shear connection (load capacity and ductility). To accurately contribute to the overall composite action, the shear connection should be designed with an optimum reinforcing ratio as expressed by Eq. (4).

$$
A_{s t} \geq \frac{0.2 R_{s h}}{f_{s d}}
$$

Where: $A_{s t}: \quad$ the required area of the reinforcing tie-bar in one shear connection;

$R_{s h}:$ the ultimate shear resistance of an individual shear connection;

$f_{s d}$ : the design value of yielding strength of the reinforcing tie-bar

The number of shear connections required to ensure full shear interaction within a critic shear span, which is define as being the length from the position of zero moment (support) to the position of the maximum bending moment, can be obtained by:

$$
N_{i}=R_{q} / R_{s h}
$$

Where:

$N_{i}: \quad$ the number of shear connectors within a critic shear span;

$R_{s h}: \quad$ the longitudinal shear resistance of an individual shear connection;

$R_{q}: \quad$ the actual longitudinal shear resistance provided by shear connections and the shear bond effect, and can be determined as:

$$
R_{q}=\left(\sigma_{c, R d} B_{e f f}\right) d
$$


Where $\sigma_{c, R d}$ is the uni-axial compressive strength of concrete; $B_{\text {eff }}$ is the effective width of concrete slab; and $d$ is the depth of concrete slab in compression.

14 push-out test results [9] and 32 numerical simulation results concerning various opening configurations (circular and clothoidal openings) are used to calibrate and to verify the proposed formulas for assessing the resistance of the shear connection. The outputs are listed in Tables 6 and 7, where the analytical results are calculated based on the proposed formulas. The mean ratios of the calculated resistances to the test results and the FE results are 0.99 and 0.76 , respectively. The proposed analytical method is found reliable and accurate in predicting the longitudinal shear resistance of the shear connection, with different shapes of web opening. However, a large variation of the predicted/test ratios can be observed in Table 6 for specimens T2 in which two reinforcing bars were used during the push out tests (one at the top of the opening and the another at the bottom). Actually, the second reinforcing bar at the bottom does not contribute to the bearing capacity of the shear connection as it was observed during the test results where it was shown that the top reinforcing bar was sheared off while the bottom one was intact. During the present calculations the two reinforcing bars were all considered, that is why the results seem to be overestimated. In these tables (Tables 6 and 7), the labels CO-FC25, CO-Tw10 and CO-O-3+Ø16 denote circular opening shape shear connection modeled with $25 \mathrm{~N} / \mathrm{mm}^{2}$ concrete compressive strength; circular opening shape shear connection modeled with $10 \mathrm{~mm}$ web thickness and circular opening shape shear connection having $16 \mathrm{~mm}$ diameter reinforcing tie-bar within the opening, respectively.

\subsection{Design of the steel section part}


Failure would also occur within the steel web post caused by the excess of longitudinal shear force from the composite action or caused by the bending moment and axial force acting on the beam, or the combination of both of them. For local composite action, the steel web post serves to introduce longitudinal shear forces into the infill concrete, that lead to significant stresses within the steel part of the shear connection. This shear transfer mechanism results in a distinctive stress concentration around the web opening. Also, global forces resulting from bending and axial forces are all redirected to the steel web post, also leading to the concentration of stresses within the steel web post. Failure in steel web post will likely occur when the beam is designed with low yielding strength and/or with relatively thin web post. Therefore, considering the above mechanism, the steel beam should be designed accordingly to enable a ductile performance for the shear connection. The shear resistance of the steel web post can be evaluated as given by Eq. (7):

$$
R_{s w}=0.25 S t_{w} f_{y}
$$

Where: $R_{s w}$ : shear resistance of steel web post;

$S: \quad$ web opening spacing;

$t_{w}: \quad$ web post thickness;

$f_{y}$ : $\quad$ yield strength of steel web post

Based on the FE and analytical calculations, the stress concentration mechanism as well as the maximum stress within the steel beam can be derived and divided into the stress caused by the composite action within the opening under the longitudinal shear and the stress caused by the bending moment and axial force, as illustrated in Fig. 20. To avoid excessive stresses in steel beam, and thus premature failure in steel section rather than the concrete element, an analytical formula expressed by the Eq. (8) is 
proposed to estimate the maximum stress within the steel section. The first part of this equation represents the major stress introduced by the longitudinal shear forces from the infill concrete into the web opening (local action), while the second part accounts for the normal stresses resulting from global bending of the composite section. The factors 8.5 and 1.5 are taken to consider the stress increase due to the stress concentration at different crucial points in the steel beam.

$$
\sigma_{d}=8.5\left(\frac{V S_{y}}{t_{w} I}\right)+1.5\left(\frac{M}{I} y\right) \leq \frac{f_{y}}{\gamma_{s}}
$$

Where: $\sigma_{d}$ : maximum design stress within the steel beam;

$V: \quad$ longitudinal shear force;

$S_{y}: \quad$ static moment of the beam section;

$t_{w}: \quad$ web post thickness;

I: $\quad$ second moment of inertia of the composite section;

M: moment resistance of the composite beam;

$y: \quad$ distance between the neutral axis of the composite section and the steel web post base;

$f_{y}: \quad$ yield strength of the steel beam section;

$\gamma_{s}: \quad$ partial safety factor for steel section $\left(\gamma_{s}=1.25\right)$

\section{Conclusion}

Shear transfer mechanism of the innovative shear connection system used in shallow cellular composite floor beams is studied. The shear connection systems are formed by combining the cast-in-place concrete passing through the web openings with reinforcing tie-bars. 40 push-out shear connection specimens of different configurations are studied by means FE simulation, in addition to 14 push-out test 
results. The findings are analyzed and used to develop a tentative design method for the shear connection. The main conclusions are drawn as follows:

(1) Failure mechanisms of the shear connection in the bending and push-out tests are confirmed in the numerical simulations. i.e. one part of the infill concrete element failed in local compression and was crushed by the steel web moving in the longitudinal direction of the shear force while the rest of the infill concrete failed in tensile splitting.

(2) The load capacity of the shear connection will depend on the area of the infill concrete element, which finally contributes toward the local compression resistance and the tensile splitting resistance of the shear connection. However, the size of the infill concrete slightly influences the slip capacity and slip stiffness of the shear connection.

(3) The concrete strength has significant influence on the load capacity; slip capacity; the longitudinal shear transfer mechanism and the failure pattern of the shear connection system.

(4) The shear connection without tie-bar element experienced a brittle failure mode. In contrast, shear connections with infill concrete and the reinforcing tie-bar experience significant ductile performance with significant slip capacity as well as the shear resisting capacity. The presence of tie-bar element can enhance the tensile splitting capacity of shear connection.

(5) The infill concrete and the tie-bar elements act compositely in resisting the longitudinal shear force. The overall shear resistance resulting in a perfect combination of the resistance of both concrete and tie-bar.

(6) Tentative design equations are proposed, and the shear resistance of shear connection is considered as the sum of the bearings contributed by the 
compression strength of infill concrete, the splitting strength of infill concrete and strength of the tie-bar element.

(7) The developed design methods are found to be reliable and accurate enough in predicting the longitudinal shear resistance of this type of shear connection.

\section{Acknowledgments}

The authors appreciate greatly the National Science Foundation of the People's Republic of China for the support for this research under the Grant No.51078290. The funding, cooperation and assistance of many people from the organization are greatly acknowledged.

\section{References}

[1] Lawson RM, Mullett DL, Rackham JW. Design of asymmetric Slimflor beams using deep composite decking. The Steel Construction Institute, SCI Publication P1751859420443; 1997, 312

[2] Lawson RM, Bode H, Brekelmans JWPM, Wright PJ, Mullett DL. 'Slimflor' and 'Slimdek' construction: European developments. Journal of Structural Engineering 00392553 1999; 77(8):22-30.

[3] Lawson RM, Lim J, Hicks SJ, Simms WI. Design of composite asymmetric cellular beams and beams with large web openings. Journal of Constructional Steel Research 0143974X 2006; 62(6):614-29.

[4] Hicks S. Current trend in modern floor construction. Mag Br Constr Steelwork Assoc (BCSA) 2003; 11(1):32-3.

[5] Mullett DL. Slim floor design and construction. The Steel Construction Institute, SCI, Publication P110; 1992. 
[6] Mullett DL, Lawson RM. Slim floor construction using deep decking. The Steel Construction Institute, SCI, Publication P127; 1993

[7] Mullett DL. Composite floor system. Blackwell Science Ltd0632041439; 1998.

[8] Wang Y, Yang L, Shi Y, Zhang R. Loading capacity of composite slim frame beams. Journal of Constructional Steel Research 0143974X 2009; 65:650-61.

[9] Huo, BY and D’Mello, CA., "Shear Transfer Mechanisms in Composite Shallow Cellular Floor Beams. Journal of Constructional Steel Research, 2013; 88, 191205

[10] Chen, SM, Limazie, T and Tan, JY. Flexural behavior of shallow cellular composite floor beams with innovative shear connections. Journal of Constructional Steel Research 2015; 106: 329-346.

[11] GB50010-2010 “China National Standard: Code for Design of Concrete Structures”. China Building Industry Press, Beijing, 2010

[12] ENV1994-1-1. "Design of Composite steel and concrete structures, Part 1-1: General Rules and Rules for Buildings”. Eurocode 4, 2004

[13] British Standard, BS5950-3.1. Structural use of steel work in building, part 3: design in composite construction, section 3.1 code of practice for design of simple and continuous composite beams; 1990.

[14] Limazie, T. and Chen, S.M. FE modeling and numerical investigation of shallow cellular composite floor beams. Journal of Constructional Steel Research 2016; 119: 190-201

[15] Limazie, T. Shear Transferring Mechanism and Structural Behavior of Shallow Cellular Composite Slim Floor Beams with Innovative Shear Connections. Ph.D. thesis, Tongji University, Shanghai, China, 2015 


\section{Table captions:}

Table 1: Material properties of concrete (MPa)

Table 2: Comparison between the push out tests and finite element analysis results

Table 3: Summary of shear connection evaluation for different shape configuration

Table 4: Summary of shear connection evaluation for different opening sizes

Table 5: Slip and load capacity of shear connections with tie-bar elements

Table 6: Comparison between test results and analytical results obtained using Eq. (3)

Table 7: Comparison between FEA and analytical results obtained using Eq. (3) 
Tables:

Table 1: Material properties of concrete (MPa)

\begin{tabular}{|c|c|c|c|c|}
\hline \multicolumn{5}{|c|}{ Concrete } \\
\hline Specimens & $\begin{array}{c}\text { Poisson ratio } \\
(v)\end{array}$ & $\begin{array}{l}\text { Elastic modulus } \\
\left(E_{c m}\right)\end{array}$ & $\begin{array}{l}\text { Compressive strength } \\
\left(f_{c}\right)\end{array}$ & $\begin{array}{l}\text { Tensile strength } \\
\left(f_{t}\right)\end{array}$ \\
\hline T5-1 & 0.2 & 34000 & 35 & 3.25 \\
\hline T5-4 & 0.2 & 32800 & 30 & 2.85 \\
\hline \multicolumn{5}{|c|}{ Steel beam } \\
\hline Specimens & $\begin{array}{c}\text { Poisson ratio } \\
(v)\end{array}$ & $\begin{array}{l}\text { Elastic modulus } \\
\left(E_{s}\right)\end{array}$ & Yielding strength $\left(f_{y}\right)$ & $\begin{array}{c}\text { Ultimate strength } \\
\left(f_{u}\right)\end{array}$ \\
\hline T5-1/T5-4 & 0.3 & 200000 & 420 & 590 \\
\hline
\end{tabular}




\section{Tables:}

Table 2: Comparison between the push out tests and finite element analysis results

\begin{tabular}{lccc|ccc}
\hline \multirow{2}{*}{ Specimens } & \multicolumn{3}{c|}{ Ultimate slip $(\mathrm{mm})$} & \multicolumn{3}{c}{ Ultimate load $(\mathrm{kN})$} \\
\cline { 2 - 7 } & Exp. & FEA & Exp/FEA & Exp. & FEA & Exp/FEA \\
\hline T5-1 & 4.84 & 4.78 & 1.01 & 227 & 230.39 & 0.98 \\
T5-3 & 3.92 & 3.93 & 0.99 & 182 & 192.35 & 0.95 \\
Average & & & $\mathbf{1 . 0}$ & & & $\mathbf{0 . 9 6}$ \\
\hline
\end{tabular}

Exp: experimental result; FEA: finite element analysis result 
Tables:

Table 3: Summary of shear connection evaluation for different shape configuration

\begin{tabular}{lccc}
\hline Specimens & $\begin{array}{c}\text { Load capacity: } P_{\max } \\
(\mathrm{kN})\end{array}$ & $\begin{array}{c}\text { Slip capacity: } \delta_{\max } \\
(\mathrm{mm})\end{array}$ & $\begin{array}{c}\text { Stiffness: } K \\
(\mathrm{kN} / \mathrm{mm})\end{array}$ \\
\hline CO-O & 188.95 & 4.01 & 47.12 \\
CL-C & 180.28 & 3.66 & 49.25 \\
CL-CE & 154.30 & 3.12 & 49.45 \\
CL-Z & 165.66 & 3.44 & 48.16 \\
\hline
\end{tabular}




\section{Tables:}

Table 4: Summary of shear connection evaluation for different opening sizes

\begin{tabular}{ccccc}
\hline Specimens & $\begin{array}{c}\text { Concrete } \\
\text { size }\left(\mathrm{mm}^{2}\right)\end{array}$ & $\begin{array}{c}\text { Load capacity: } P_{\max } \\
(\mathrm{kN})\end{array}$ & $\begin{array}{c}\text { Slip capacity: } \delta_{\max } \\
(\mathrm{mm})\end{array}$ & $\begin{array}{c}\text { Stiffness: } K \\
(\mathrm{kN} / \mathrm{mm})\end{array}$ \\
\hline CO-O-1 & 14000 & 188.95 & 4.01 & 47.12 \\
CO-O-2 & 8400 & 124.72 & 3.04 & 41.03 \\
CO-O-3 & 4200 & 83.77 & 3.00 & 27.92 \\
CL-C-1 & 14000 & 180.28 & 3.66 & 49.25 \\
CL-C-2 & 8400 & 126.98 & 2.94 & 43.19 \\
CL-C-3 & 4200 & 94.84 & 3.45 & 27.49 \\
\hline
\end{tabular}


Tables:

Table 5: Slip and load capacity of shear connections with tie-bar elements

\begin{tabular}{cccccc}
\hline Specimens & $\begin{array}{c}\text { Concrete } \\
\text { size }\left(\mathrm{mm}^{2}\right)\end{array}$ & $\begin{array}{c}\text { Load: } P_{\max } \\
(\mathrm{kN})\end{array}$ & $\begin{array}{c}\text { Tie-bar } \\
\text { resistance }(\mathrm{kN})\end{array}$ & $\begin{array}{c}\text { Slip capacity: } \\
\delta_{\max }(\mathrm{mm})\end{array}$ & $\begin{array}{c}\text { Stiffness: } K \\
(\mathrm{kN} / \mathrm{mm})\end{array}$ \\
\hline CO-O-3 & 4200 & 83.8 & -- & 3.0 & 27.9 \\
CO-O-3+Ø8 & 4200 & 101.0 & 17.23 & 4.7 & 28.8 \\
CO-O-3+Ø10 & 4200 & 113.5 & 29.7 & 5.5 & 27.4 \\
CO-O-3+Ø12 & 4200 & 132.6 & 48.8 & 6.4 & 27.6 \\
CO-O-3+Ø14 & 4200 & 144.4 & 60.6 & 6.6 & 28.5 \\
CO-O-3+Ø16 & 4200 & 153.5 & 69.7 & 6.7 & 26.5 \\
CO-O-3+Ø20 & 4200 & 162.2 & 78.4 & 6.9 & 28.8 \\
CL-C-1 & 14000 & 180.3 & -- & 3.6 & 50.1 \\
CL-C-1+Ø8 & 14000 & 199.1 & 18.8 & 3.6 & 56.8 \\
CL-C-1+Ø12 & 14000 & 252.0 & 71.7 & 5.4 & 57.2 \\
CL-C-1+Ø16 & 14000 & 297.3 & 117.0 & 5.9 & 56.1 \\
\hline
\end{tabular}


Tables:

Table 6: Comparison between test results and analytical results obtained using Eq. (3)

\begin{tabular}{|c|c|c|c|c|c|c|c|c|c|}
\hline Specimen & $\begin{array}{c}f_{c u} \\
\mathbf{M P a}\end{array}$ & $\begin{array}{c}f_{c t} \\
\mathbf{M P a}\end{array}$ & $\begin{array}{c}A_{c} \\
\mathbf{m m}^{2}\end{array}$ & $\begin{array}{c}h_{D} \\
\text { mm }\end{array}$ & $\begin{array}{c}\boldsymbol{t}_{w} \\
\mathbf{m m}\end{array}$ & $\emptyset_{t b}$ & $\begin{array}{c}\text { Anal. } \\
\text { kN }\end{array}$ & $\begin{array}{r}\text { Exp } \\
\text { kN }\end{array}$ & Anal/Exp \\
\hline T1-B-N & 55.6 & 4.53 & 31416 & 200 & 9.9 & -- & 429 & 362 & 1.18 \\
\hline T1-B-F & 58.1 & 4.85 & 31416 & 200 & 9.9 & -- & 455 & 397 & 1.14 \\
\hline T5-1 & 35 & 3.21 & 17671 & 150 & 8.6 & -- & 173 & 226 & 0.76 \\
\hline T5-2 & 35 & 3.21 & 17671 & 150 & 8.6 & -- & 173 & 194 & 0.89 \\
\hline T5-3 & 32 & 2.9 & 17671 & 150 & 8.6 & -- & 157 & 182 & 0.86 \\
\hline T5-4 & 30 & 3.02 & 17671 & 150 & 8.6 & -- & 158 & 175 & 0.90 \\
\hline T2-A-N & 54.5 & 4.54 & 17671 & 150 & 8.6 & $2 \varnothing 12$ & 426 & 309 & 1.37 \\
\hline T2-A-F & 51.9 & 4.07 & 17671 & 150 & 8.6 & $2 \varnothing 12$ & 384 & 305 & 1.25 \\
\hline T2-B-N & 54.5 & 4.54 & 31416 & 200 & 9.9 & $2 \varnothing 12$ & 584 & 390 & 1.45 \\
\hline T2-B-F & 51.9 & 4.07 & 31416 & 200 & 9.9 & $2 \varnothing 12$ & 526 & 372 & 1.41 \\
\hline T6-1 & 29 & 2.85 & 17671 & 150 & 8.6 & $1 \varnothing 16$ & 259 & 391 & 0.66 \\
\hline T6-2 & 32 & 2.92 & 17671 & 150 & 8.6 & $1 \varnothing 16$ & 269 & 386 & 0.70 \\
\hline T6-3 & 28 & 2.49 & 17671 & 150 & 8.6 & $1 \varnothing 16$ & 230 & 327 & 0.70 \\
\hline T6-4 & 27 & 2.57 & 17671 & 150 & 8.6 & $1 \varnothing 16$ & 235 & 358 & 0.66 \\
\hline \multicolumn{9}{|c|}{ Average: } & 0.99 \\
\hline
\end{tabular}

Notes: Exp": push out test results (Huo et al.) ${ }^{\text {|9]; }}$ Anal.: analytical results from Eq. (3); $\boldsymbol{\emptyset}_{t b}$ : diameter of the tie-bar; $\boldsymbol{t}_{w}$ : steel web thickness; $\boldsymbol{h}_{\boldsymbol{D}}$ : depth of the web opening; $A_{c}$ : area of infill concrete; $\boldsymbol{f}_{c t}$ : tensile splitting strength of concrete; $f_{c u}$ : cube compressive strength of concrete. 
Tables:

Table 7: Comparison between FEA and analytical results obtained using Eq. (3)

\begin{tabular}{|c|c|c|c|c|c|c|c|c|c|}
\hline Specimen & $\begin{array}{c}f_{c u} \\
\left(\mathbf{N} / \mathbf{m m}^{2}\right)\end{array}$ & $\begin{array}{c}f_{c t} \\
\left(\mathbf{N} / \mathbf{m m}^{2}\right)\end{array}$ & $\begin{array}{c}A_{c} \\
\left(\mathbf{m m}^{2}\right)\end{array}$ & $\begin{array}{c}h_{D} \\
(\mathbf{m m})\end{array}$ & $\begin{array}{c}\boldsymbol{t}_{w} \\
(\mathbf{m m})\end{array}$ & $\emptyset_{t b}$ & $\begin{array}{c}\text { Anal. } \\
(\mathbf{k N})\end{array}$ & $\begin{array}{l}\text { FEA } \\
(\mathbf{k N})\end{array}$ & Anal/FEA \\
\hline CO-1 & 30 & 2.10 & 14000 & 134 & 14 & -- & 130 & 189 & 0.69 \\
\hline $\mathrm{CO}-2$ & 30 & 2.10 & 8400 & 103.5 & 14 & -- & 105 & 125 & 0.84 \\
\hline $\mathrm{CO}-3$ & 30 & 2.10 & 4200 & 73.2 & 14 & -- & 56 & 84 & 0.67 \\
\hline CL-C-1 & 30 & 2.10 & 14000 & 124 & 14 & -- & 124 & 180 & 0.69 \\
\hline CL-C-2 & 30 & 2.10 & 8400 & 96.5 & 14 & -- & 99 & 127 & 0.78 \\
\hline CL-C-3 & 30 & 2.10 & 4200 & 68.5 & 14 & -- & 81 & 95 & 0.85 \\
\hline CL-CE & 30 & 2.10 & 14000 & 100 & 14 & -- & 112 & 154 & 0.73 \\
\hline CL-Z & 30 & 2.10 & 14000 & 100 & 14 & -- & 117 & 165 & 0.71 \\
\hline CO-FC25 & 25 & 1.80 & 14000 & 134 & 14 & -- & 109 & 141 & 0.77 \\
\hline CO-FC30 & 30 & 2.10 & 14000 & 134 & 14 & -- & 130 & 189 & 0.69 \\
\hline $\mathrm{CO}-\mathrm{FC} 40$ & 40 & 2.80 & 14000 & 134 & 14 & -- & 173 & 209 & 0.83 \\
\hline CO-FC50 & 50 & 3.50 & 14000 & 134 & 14 & -- & 215 & 302 & 0.72 \\
\hline CL-C-FC25 & 25 & 1.80 & 14000 & 124 & 14 & -- & 105 & 157 & 0.67 \\
\hline CL-C-FC30 & 30 & 2.10 & 14000 & 124 & 14 & -- & 125 & 180 & 0.69 \\
\hline CL-C-FC40 & 40 & 2.80 & 14000 & 124 & 14 & -- & 157 & 239 & 0.66 \\
\hline CL-C-FC50 & 50 & 3.50 & 14000 & 124 & 14 & -- & 207 & 296 & 0.70 \\
\hline CO-Tw10 & 30 & 2.10 & 14000 & 134 & 10 & -- & 110 & 151 & 0.73 \\
\hline CO-Tw14 & 30 & 2.10 & 14000 & 134 & 14 & -- & 130 & 189 & 0.69 \\
\hline CO-Tw20 & 30 & 2.10 & 14000 & 134 & 20 & -- & 159 & 265 & 0.60 \\
\hline CL-C-Tw10 & 30 & 2.10 & 14000 & 124 & 10 & -- & 106 & 127 & 0.84 \\
\hline CL-C-Tw14 & 30 & 2.10 & 14000 & 124 & 14 & -- & 124 & 180 & 0.69 \\
\hline CL-C-Tw20 & 30 & 2.10 & 14000 & 124 & 20 & -- & 151 & 221 & 0.69 \\
\hline $\begin{array}{c}\text { CO-O- } \\
3+\varnothing 8\end{array}$ & 30 & 2.10 & 4200 & 73.2 & 14 & $1 \varnothing 8$ & 77 & 101 & 0.75 \\
\hline $\begin{array}{l}\mathrm{CO}-\mathrm{O}- \\
3+\varnothing 10 \\
\end{array}$ & 30 & 2.10 & 4200 & 73.2 & 14 & $1 \varnothing 10$ & 88 & 113 & 0.78 \\
\hline $\begin{array}{l}\mathrm{CO}-\mathrm{O}- \\
3+\varnothing 12\end{array}$ & 30 & 2.10 & 4200 & 73.2 & 14 & $1 \varnothing 12$ & 103 & 133 & 0.77 \\
\hline $\begin{array}{l}\mathrm{CO}-\mathrm{O}- \\
3+\varnothing 14 \\
\end{array}$ & 30 & 2.10 & 4200 & 73.2 & 14 & $1 \varnothing 14$ & 120 & 144 & 0.83 \\
\hline $\begin{array}{l}\text { CO-O- } \\
3+\varnothing 16\end{array}$ & 30 & 2.10 & 4200 & 73.2 & 14 & $1 \varnothing 16$ & 139 & 153 & 0.91 \\
\hline $\begin{array}{l}\text { CO-O- } \\
3+\varnothing 20\end{array}$ & 30 & 2.10 & 4200 & 73.2 & 14 & $1 \varnothing 20$ & 186 & 162 & 1.14 \\
\hline CL-C-1+Ø8 & 30 & 2.10 & 14000 & 124 & 14 & $1 \varnothing 8$ & 145 & 199 & 0.73 \\
\hline $\begin{array}{l}\text { CL-C- } \\
1+\emptyset 12 \\
\end{array}$ & 30 & 2.10 & 14000 & 124 & 14 & $1 \varnothing 12$ & 171 & 252 & 0.68 \\
\hline $\begin{array}{l}\text { CL-C- } \\
1+\varnothing 16\end{array}$ & 30 & 2.10 & 14000 & 124 & 14 & $1 \varnothing 16$ & 208 & 297 & 0.70 \\
\hline \multicolumn{9}{|c|}{ Average: } & 0.76 \\
\hline
\end{tabular}

Notes: FEA: finite element analysis results; Anal.: analytical results from Eq. (3); $\emptyset_{t b}$ : diameter of tiebar; $\boldsymbol{t}_{\boldsymbol{w}}$ : steel web thickness; $\boldsymbol{h}_{\boldsymbol{D}}$ : depth of the web opening; $A_{c}$ : area of infill concrete; $\boldsymbol{f}_{c \boldsymbol{c}}$ : tensile splitting strength of concrete; $f_{c u}$ : cube compressive strength of concrete. 


\section{Figure captions:}

Figure 1: Configurations of different Slim Floor system construction

Figure 2: Typical arrangement of shear connection with circular opening in shallow cellular composite floor beam

Figure 3: Configuration and components nomenclature of shear connections

Figure 4: A typical force transfer mechanism in shear connection

Figure 5: Geometrical characteristics of the push-out test specimens

Figure 6: Elements used for steel and concrete modeling

Figure 7: Meshed FE model of push-out specimen (one circular opening)

Figure 8: Typical strain-stress curves of the material used for the FE modeling

Figure 9: Comparison of load-slip curves between the push out tests and FE simulations

Figure 10: Contour plots of stresses in concrete steel for specimen T5-1

Figure 11: Geometrical configuration of a typical push-out specimen for FEA

Figure 12: Different shapes of shear connections designed for the FE simulations

Figure 13: Load-slip curves of the shear connections with different shape configuration

Figure 14: Contour plots of von Mises stress of different shear connection configuration

Figure 15: Load-slip curves of shear connections with different shear connection sizes

Figure 16: Influence of concrete strength on the load-slip behavior of shear connections

Figure 17: Influence of steel yield strength on the load-slip behavior of shear connections

Figure 18: Influence of steel web post thickness on the load-slip behavior 
Figure 19: Effects of the reinforced tie-bar element on the load-slip behavior

Figure 20: Different forces action inducing stress concentration within the steel element 
Figure 1

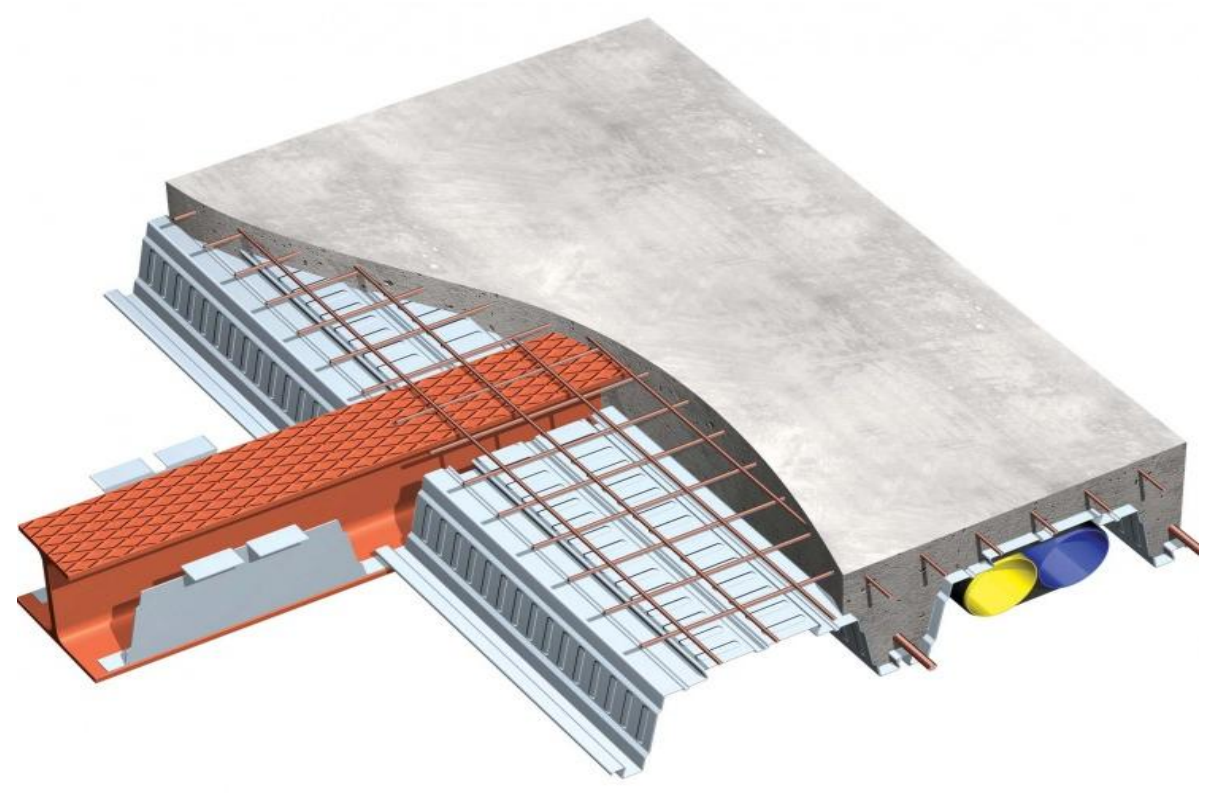

(a) Ordinary Slim Floor configuration

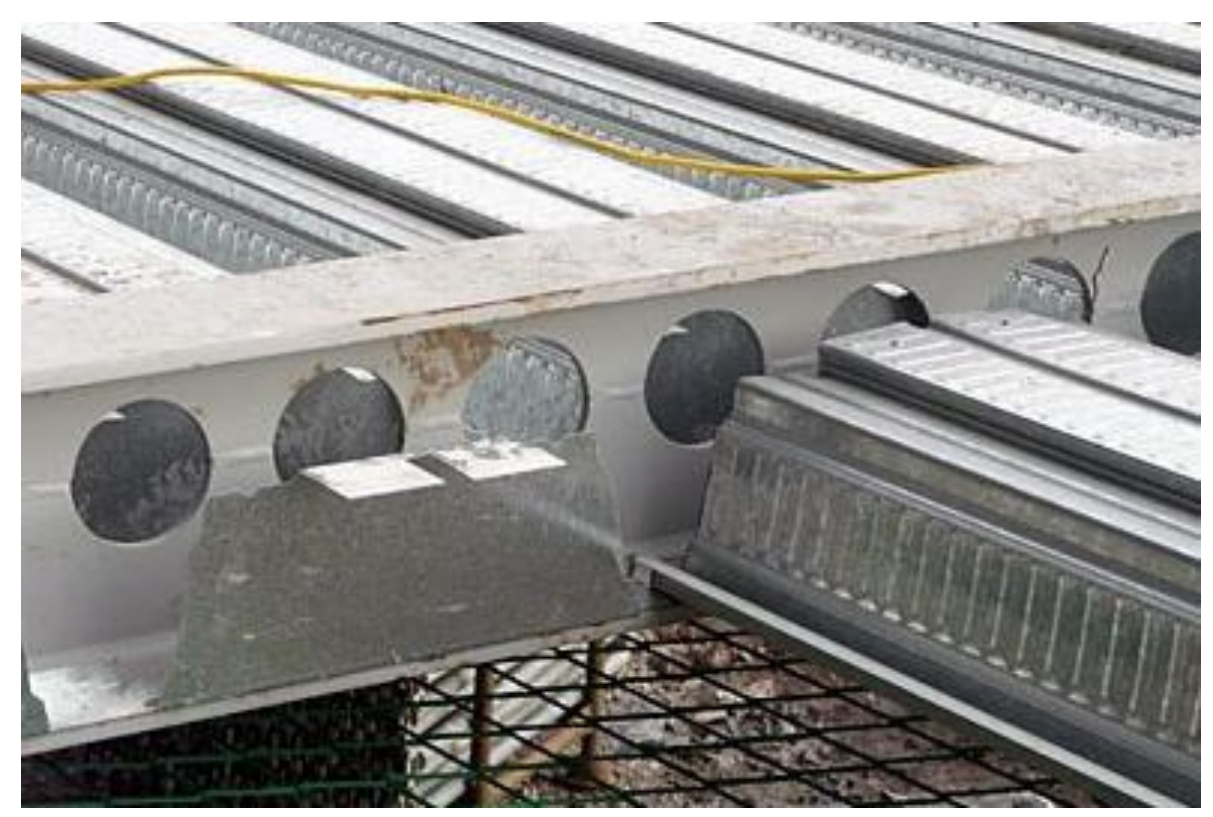

(b) SCCFB with decking configuration

Fig. 1: Configurations of different Slim Floor system construction 
Figure 2

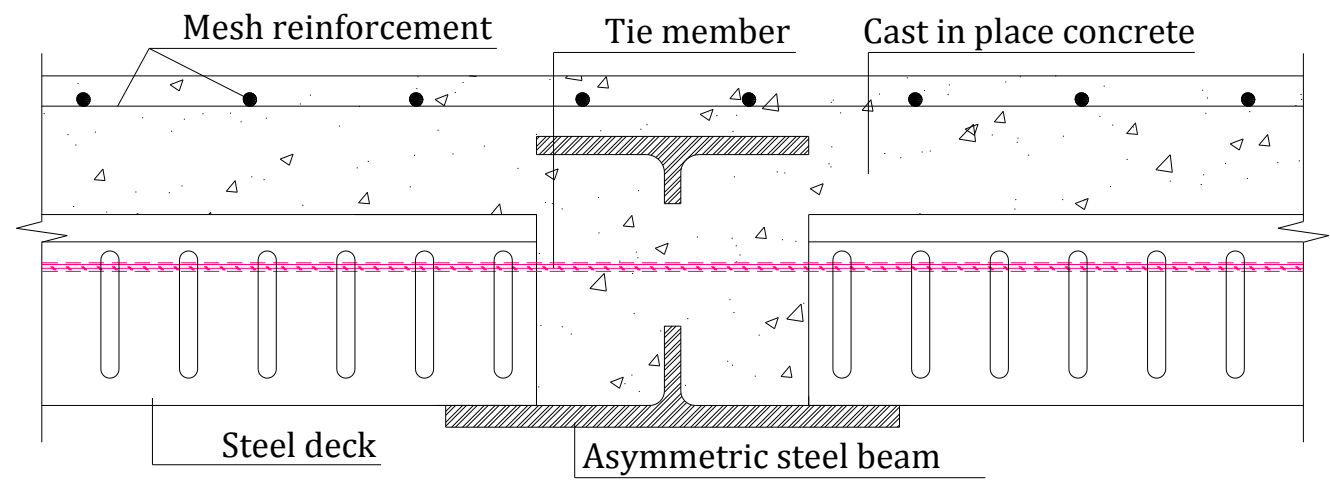

Fig. 2: Typical arrangement of shear connection with circular opening in shallow cellular composite floor beam 
Figure 3:
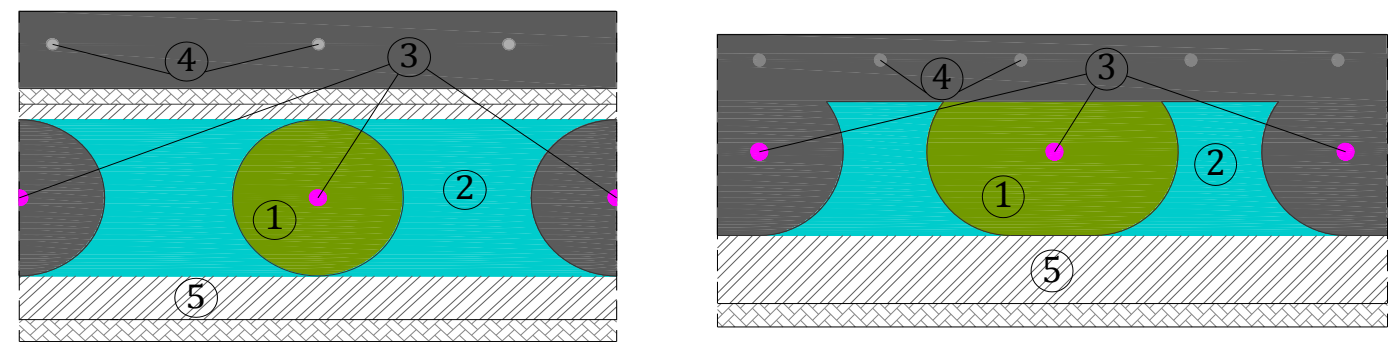

(1) Infill concrete

(2) Steel web post

(1) Infill concrete

(2) Steel web post

(3) Tie-bar element

(4) Reinforcements

(3) Tie-bar element

(4) Reinforcements

(5) Steel web base

(5) Steel web base

(a) Components of the shear connections
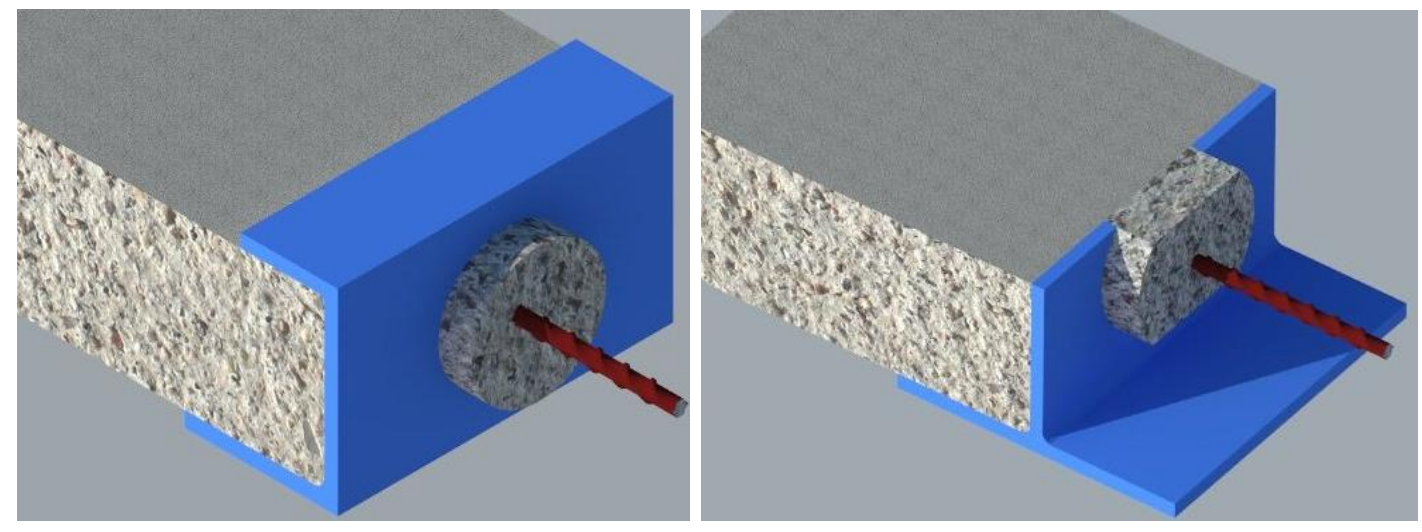

(b) Schematic configuration of the shear connections

Fig. 3: Configuration and components nomenclature of shear connections 
Figure 4:

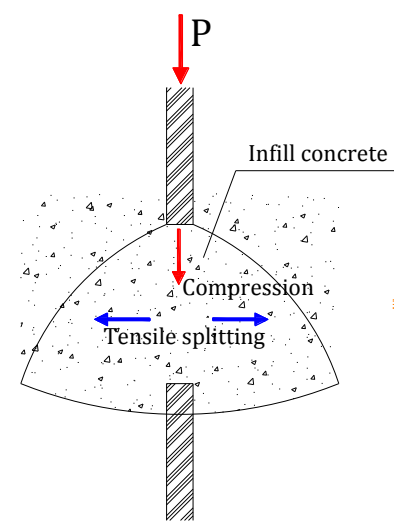

(a)

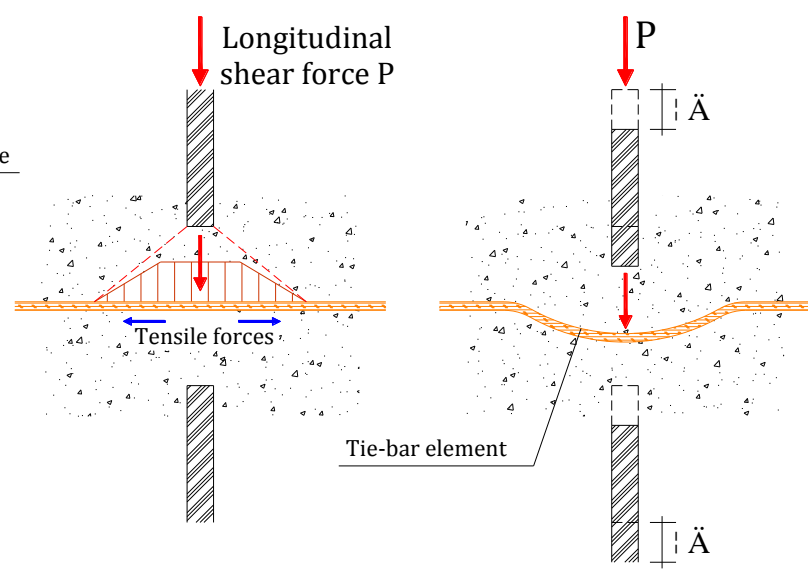

(b). (c).

Fig. 4: A typical force transfer mechanism in shear connection:

(a) Local compression action; (b) Dowel action within opening; (c) Block effect of tie-bar preventing shear progression 
Figure 5

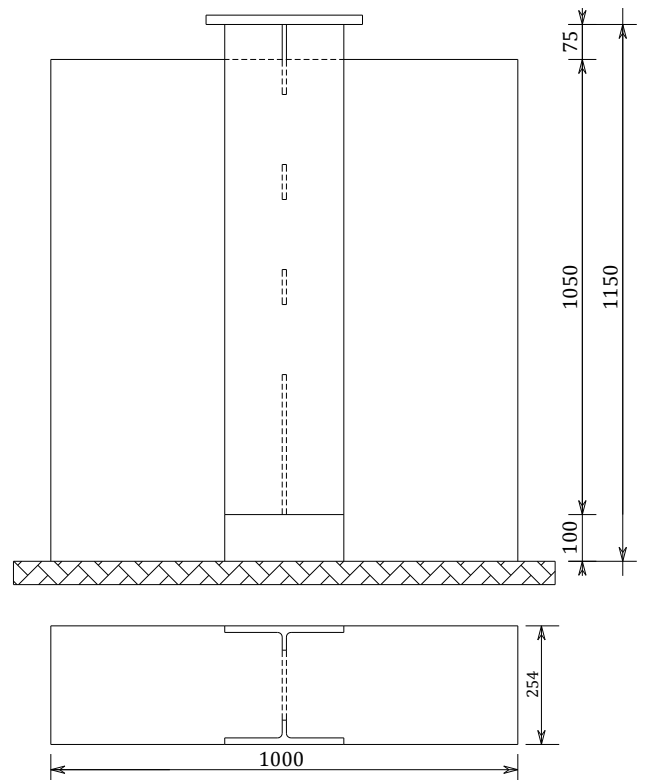

(a) Concrete slab

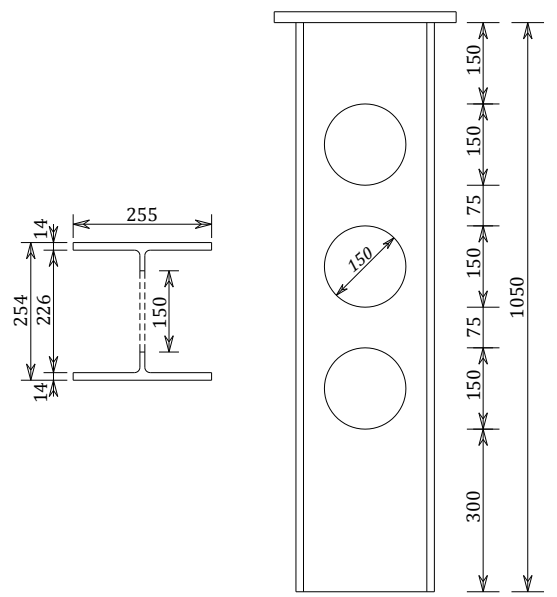

(b) Steel section

Fig. 5: Geometrical characteristics of the push-out test specimen 
Figure 6
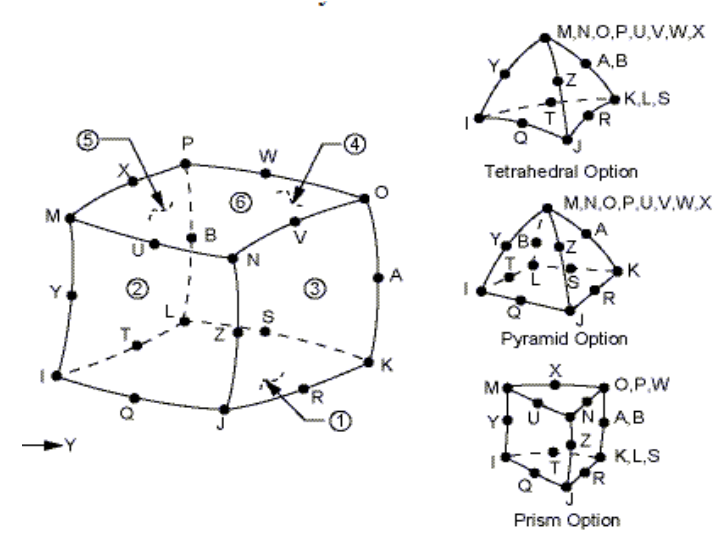

(a) Solid95 element for steel section

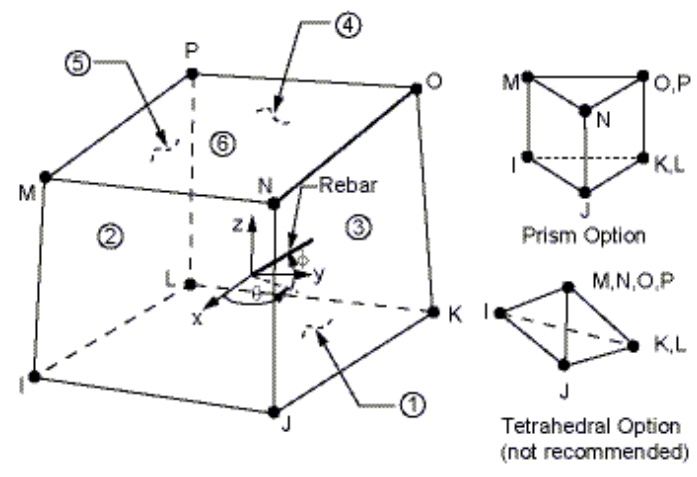

(b) Solid65 element for concrete

Fig. 6: Elements used for steel and concrete modeling 
Figure 7

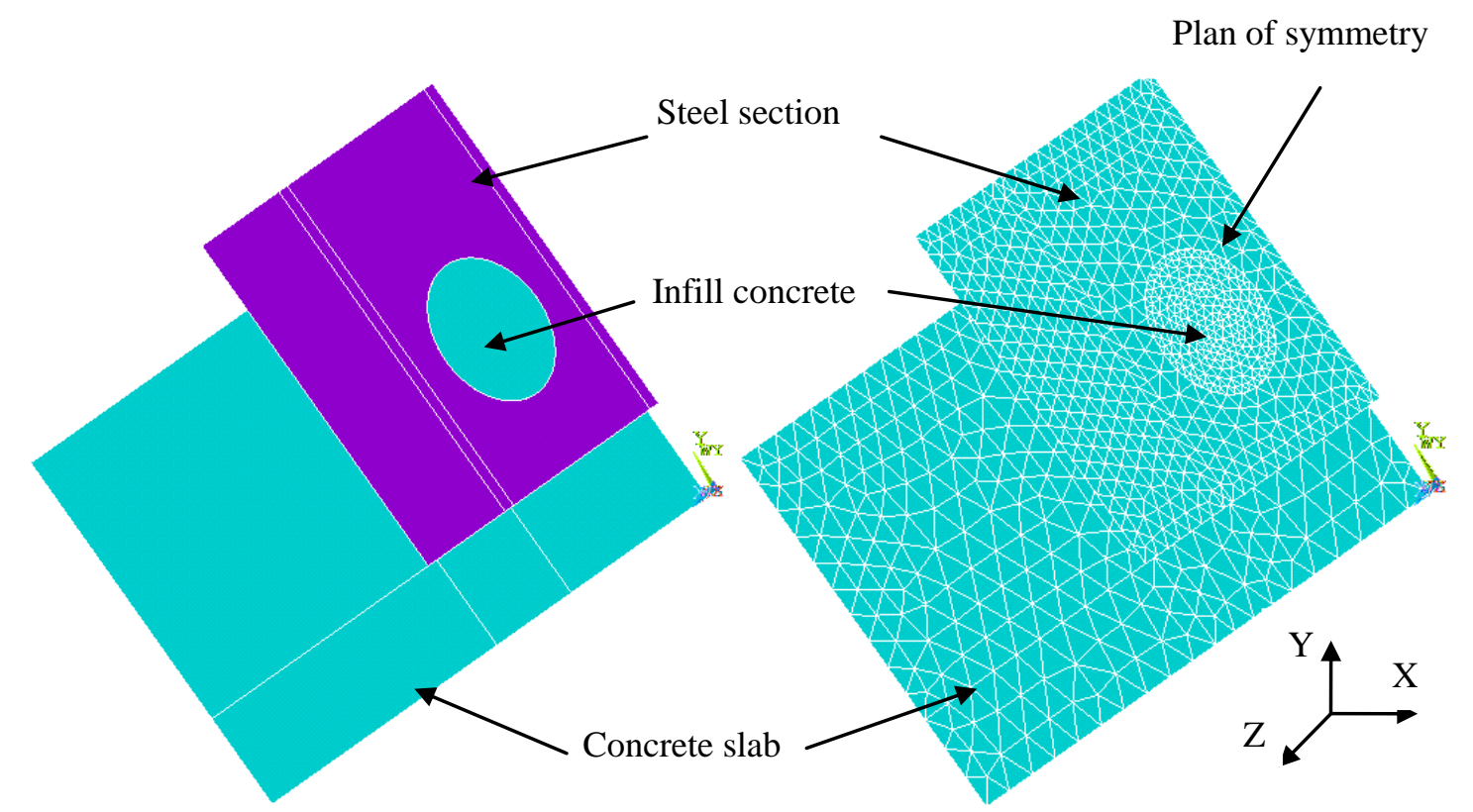

Fig. 7: Meshed FE model of push-out specimen (one circular opening) 
Figure 8

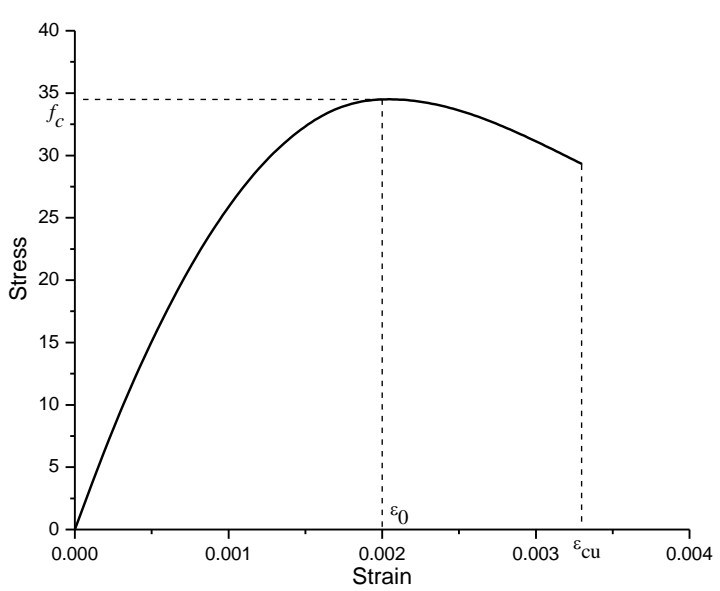

(a) Concrete

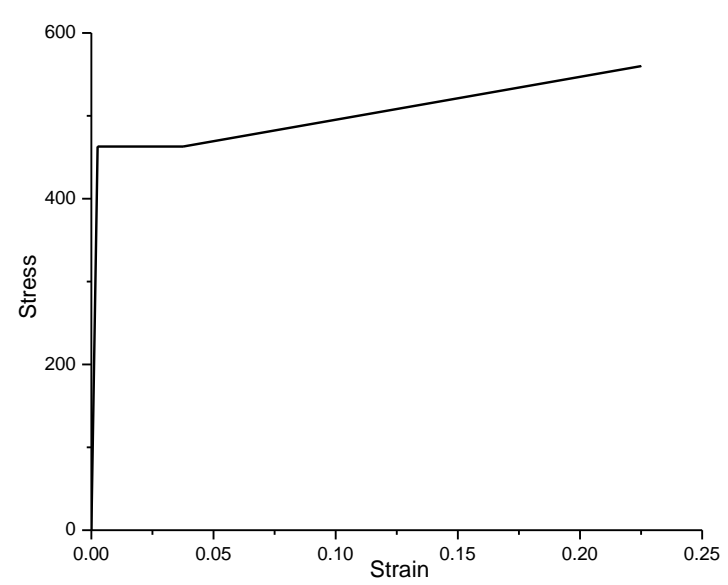

(b) Steel

Fig. 8: Typical strain-stress curves of the material used for the FE modeling 
Figure 9

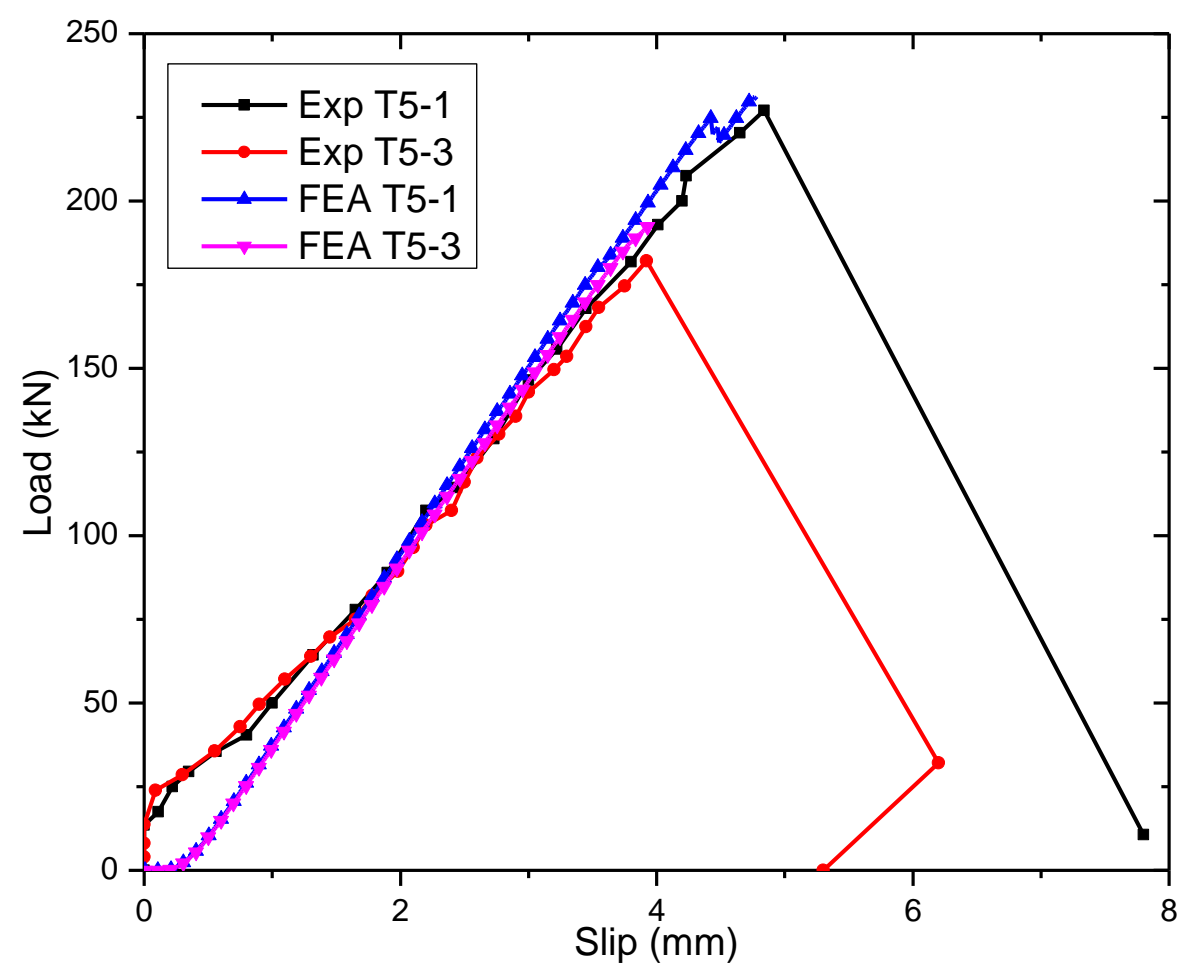

Fig. 9: Comparison of load-slip curves between the push out tests and FE simulations 
Figure 10
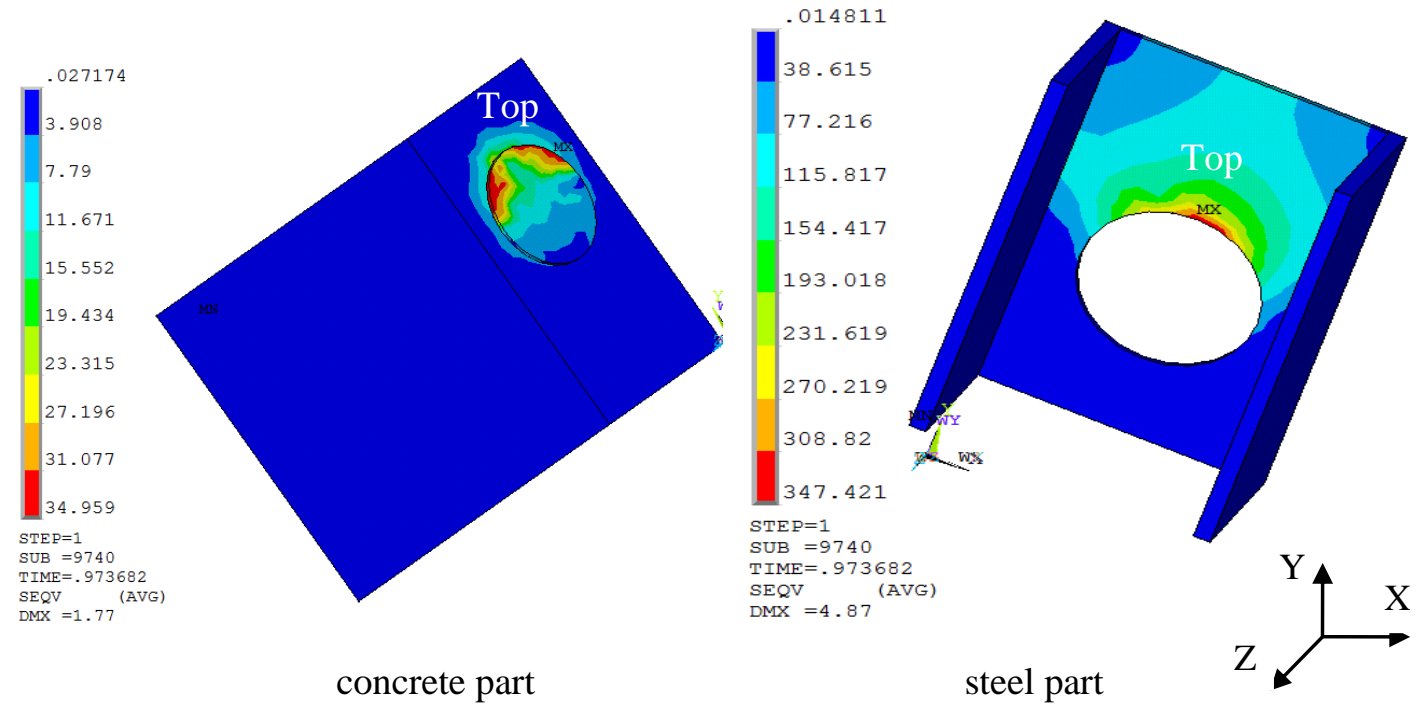

(a) Contour plots of Von Mises stress of concrete and steel

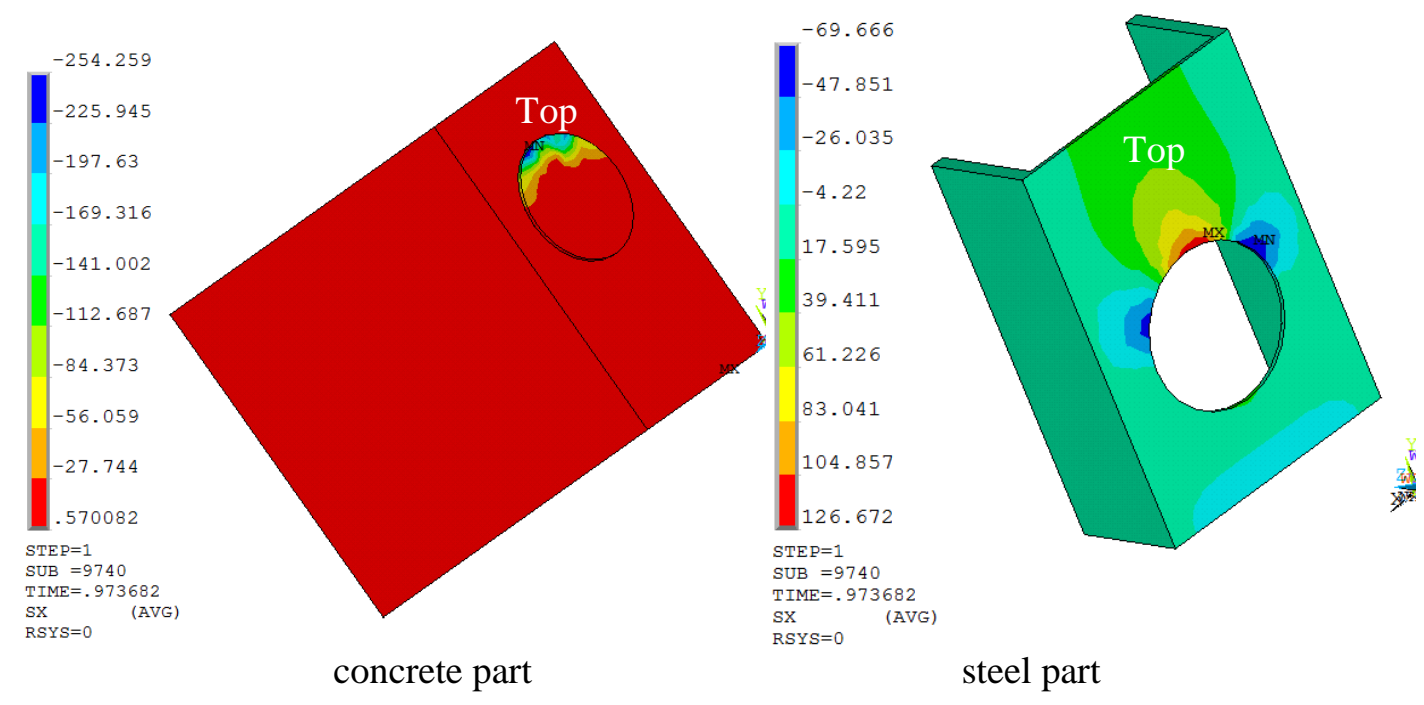

(b) Stress contour plot of concrete and steel in X direction 


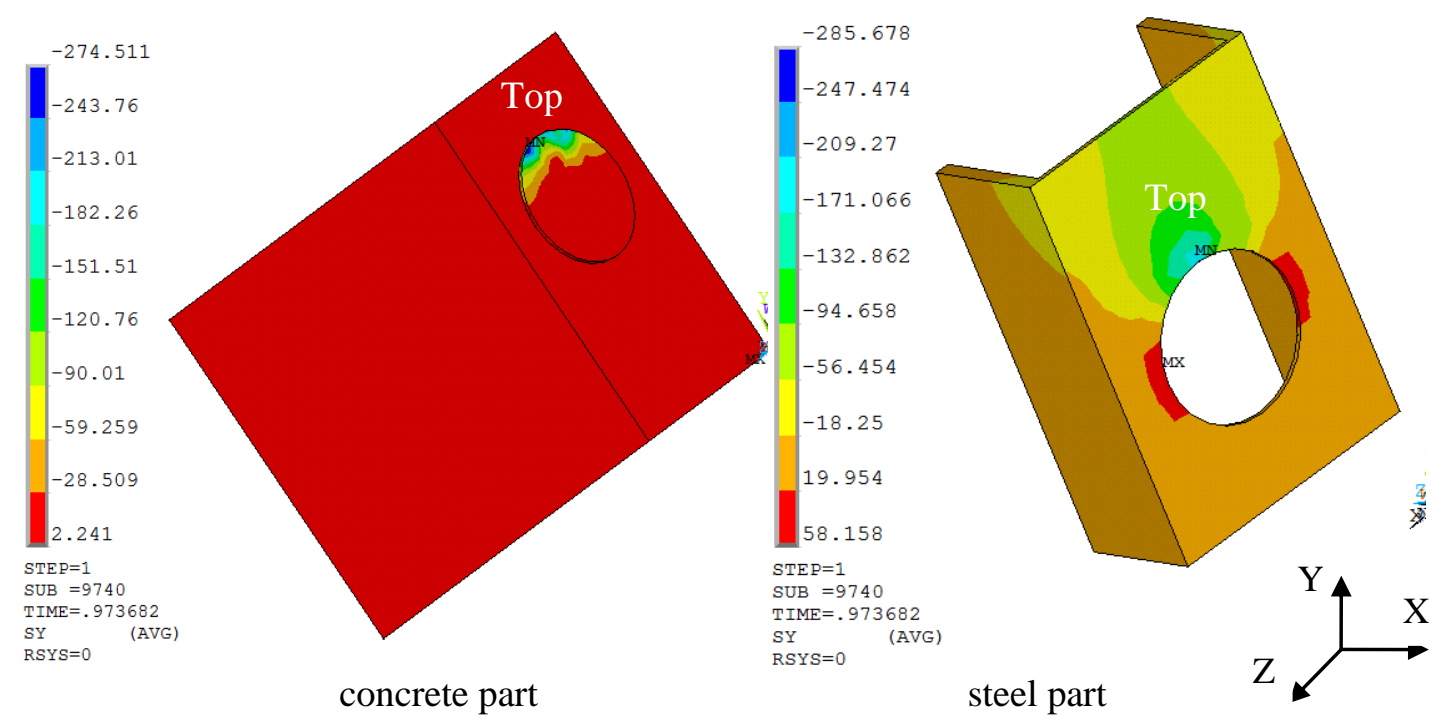

(c) Stress contour plots of concrete and steel in Y direction

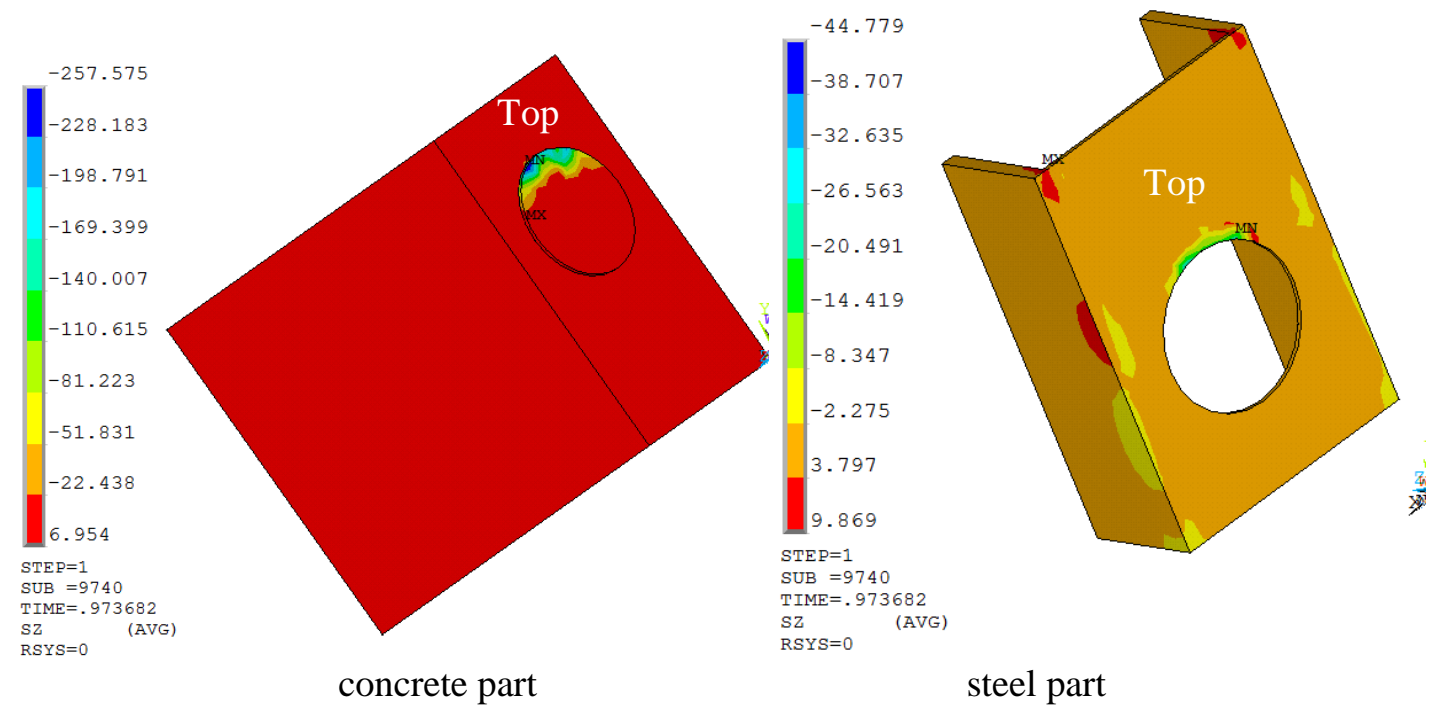

(d) Stress contour plots of concrete and steel in $\mathrm{Z}$ direction 


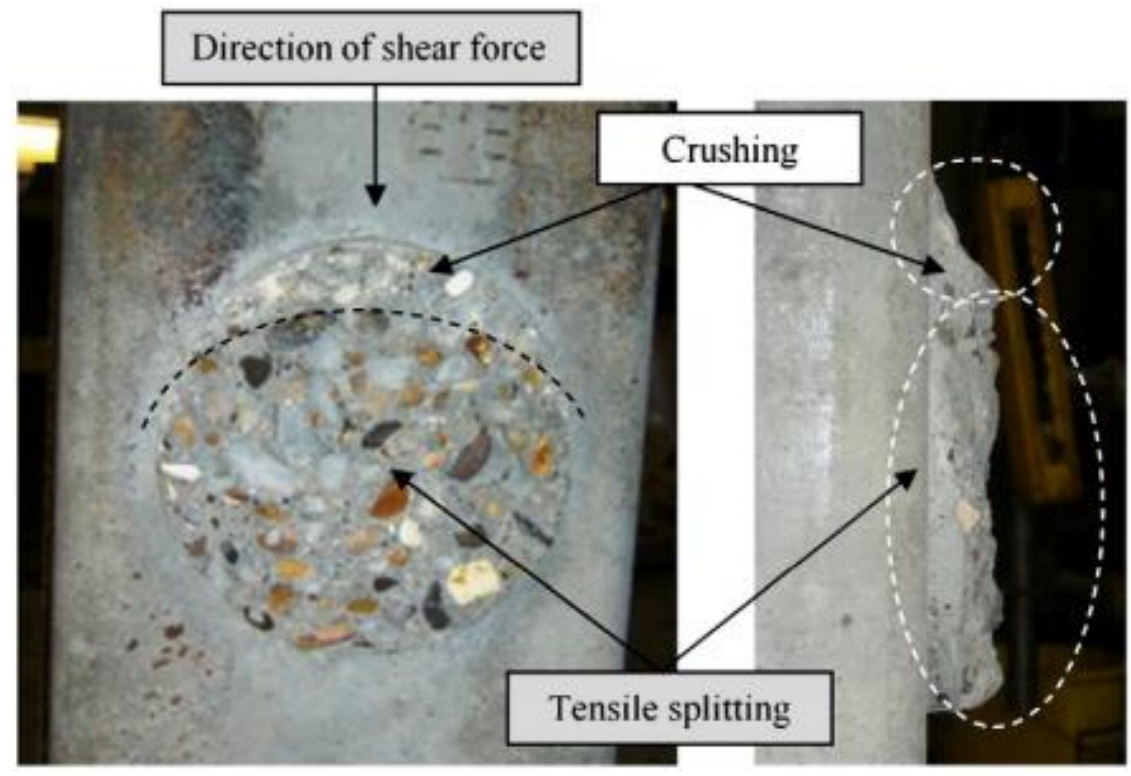

(e) Failure profile of the shear connection during the push out test [9]

Fig. 10: Comparison between the test results and contour plots of stresses in concrete steel for specimen T5-1 showing the failure mode of the shear connection 
Figure 11
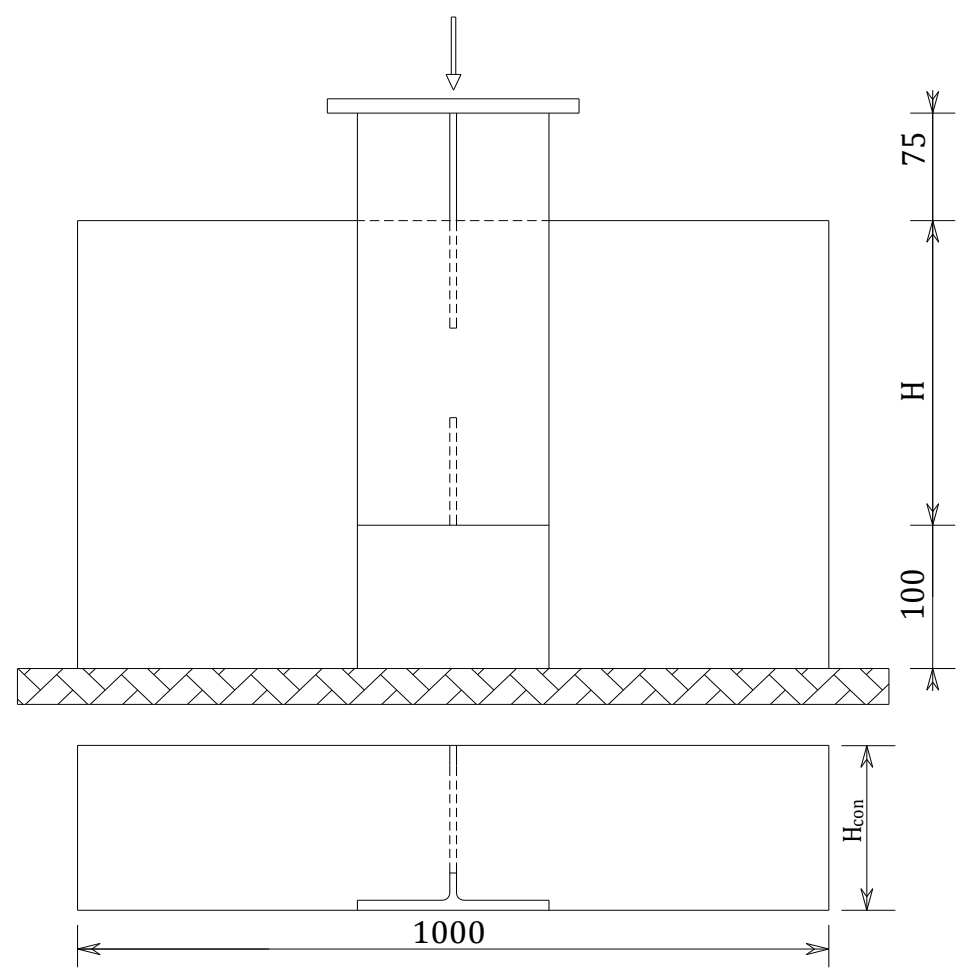

Fig. 11: Geometrical configuration of a typical push-out specimen for FEA 
Figure 12
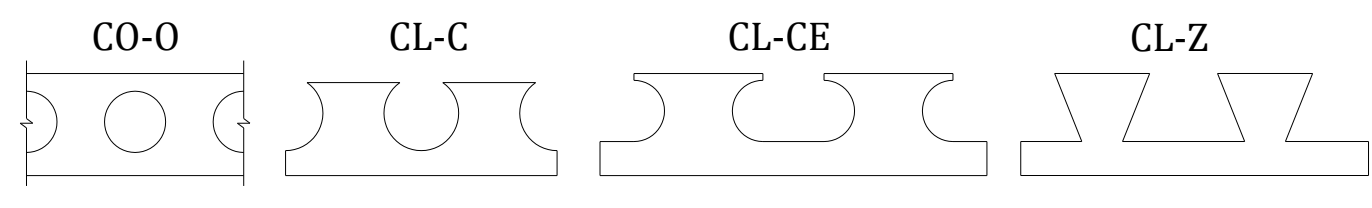

(a) Shear connection shapes
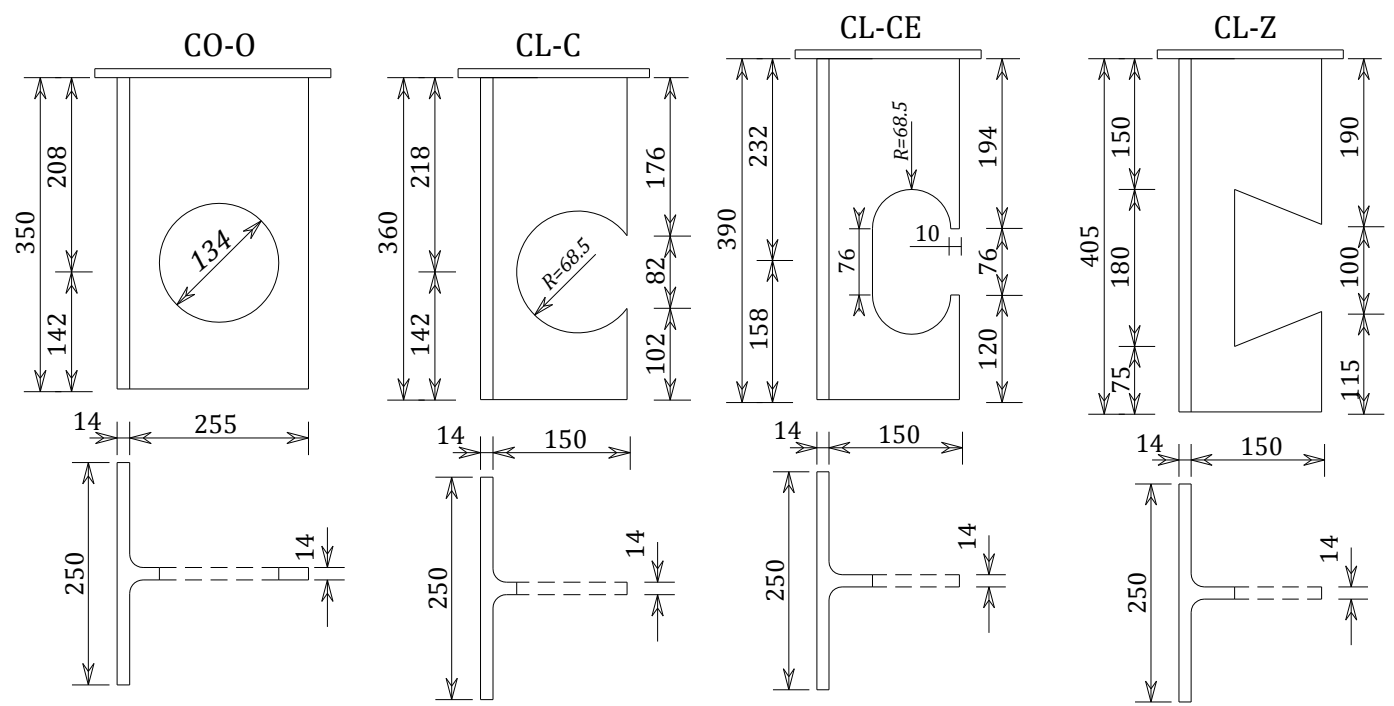

(b) Geometrical dimensions of the steel beam sections

Fig. 12: Different shapes of shear connections designed for the FE simulations 
Figure 13

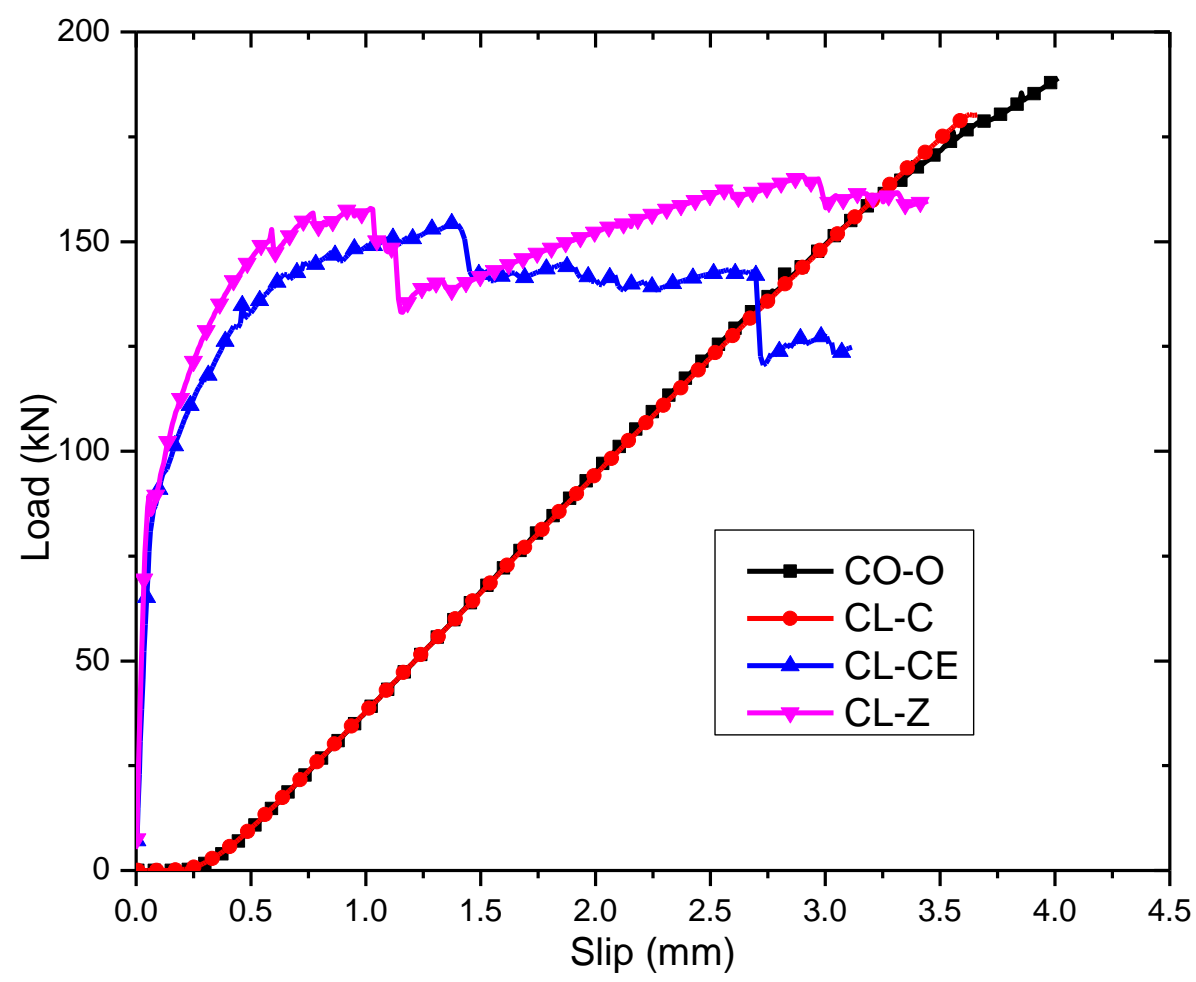

Fig. 13: Load-slip curves of the shear connections with different shape configuration 
Figure 14

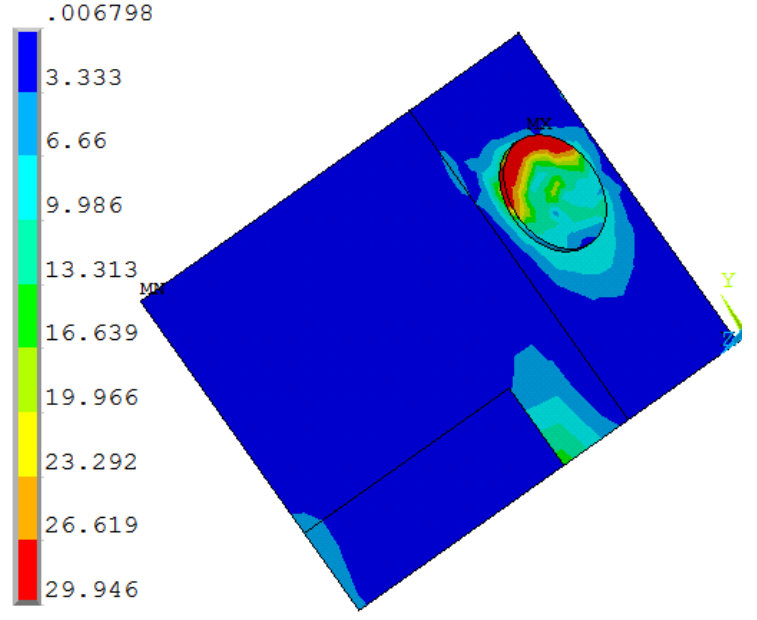

Concrete element

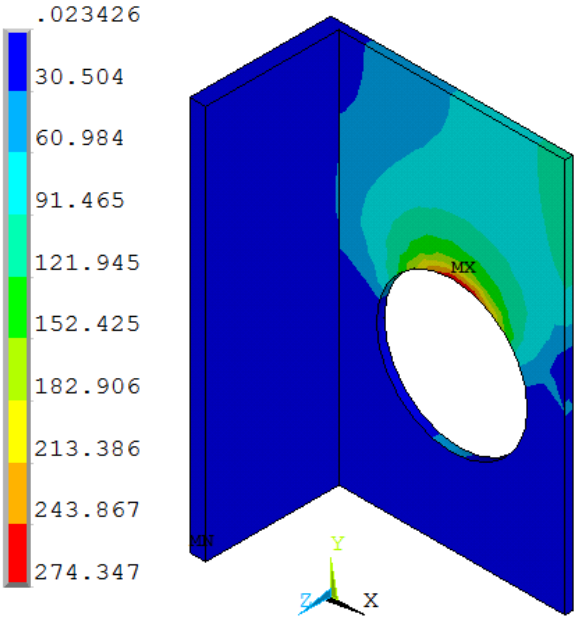

Steel element

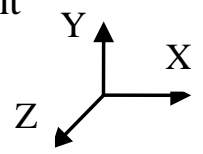

(a) Circular opening (CO-O shape)

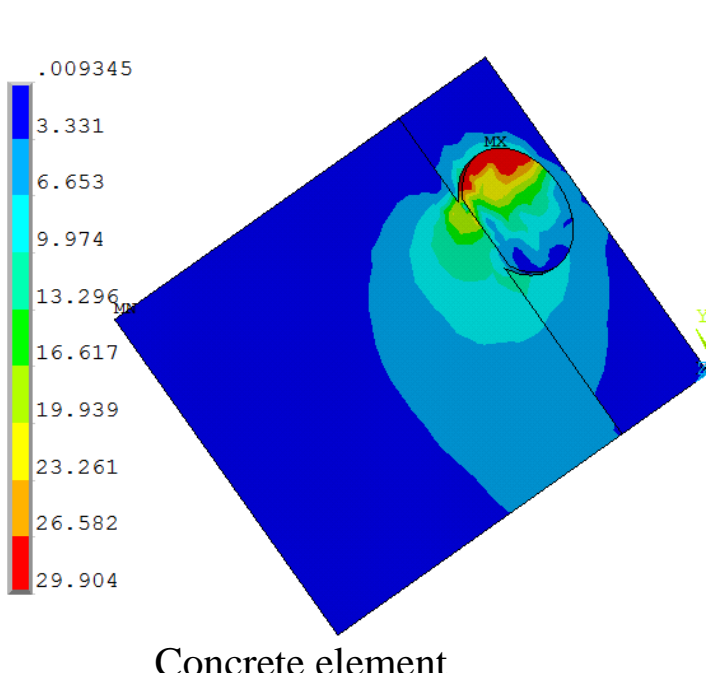

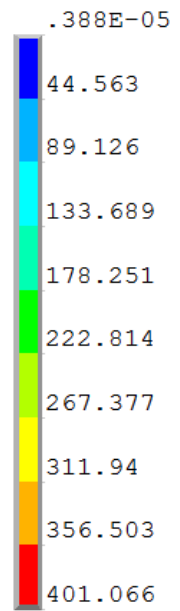

Steel element

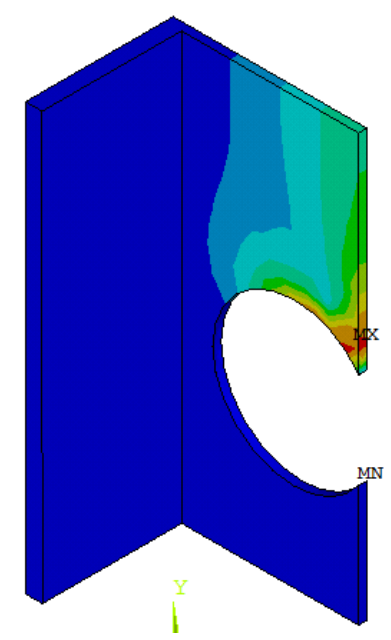

(b) Clothoidal opening (CL-C shape) 


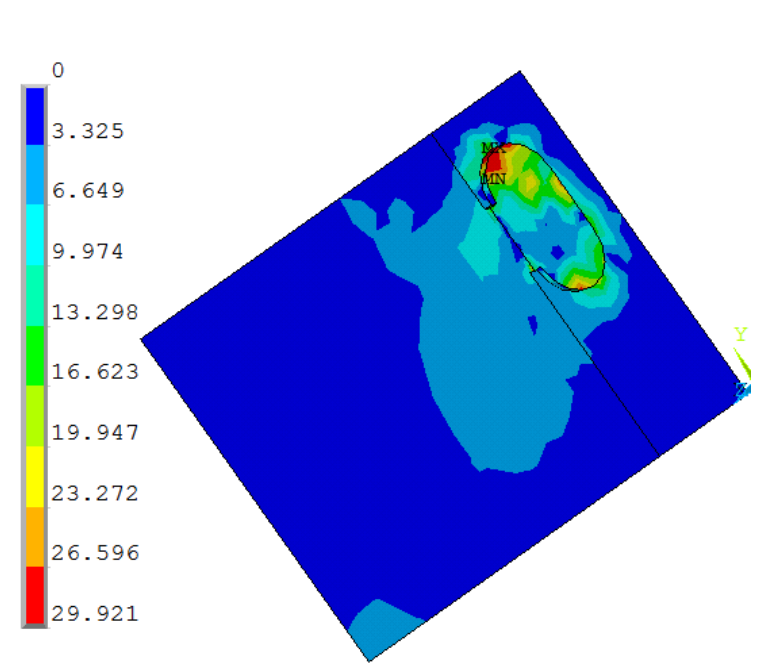

Concrete element

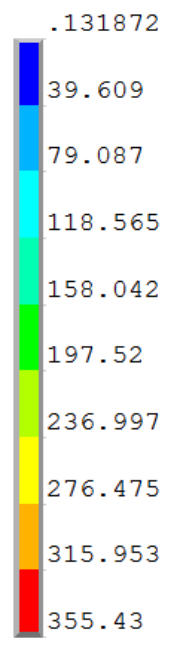

Steel element
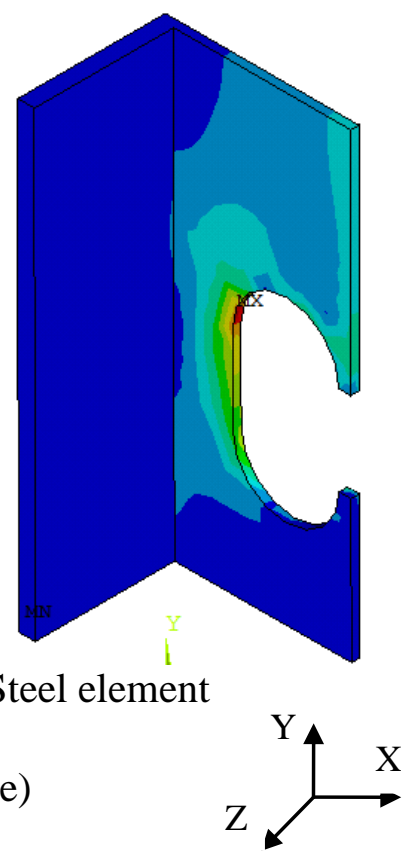

(c) Clothoidal opening (CL-CE shape)
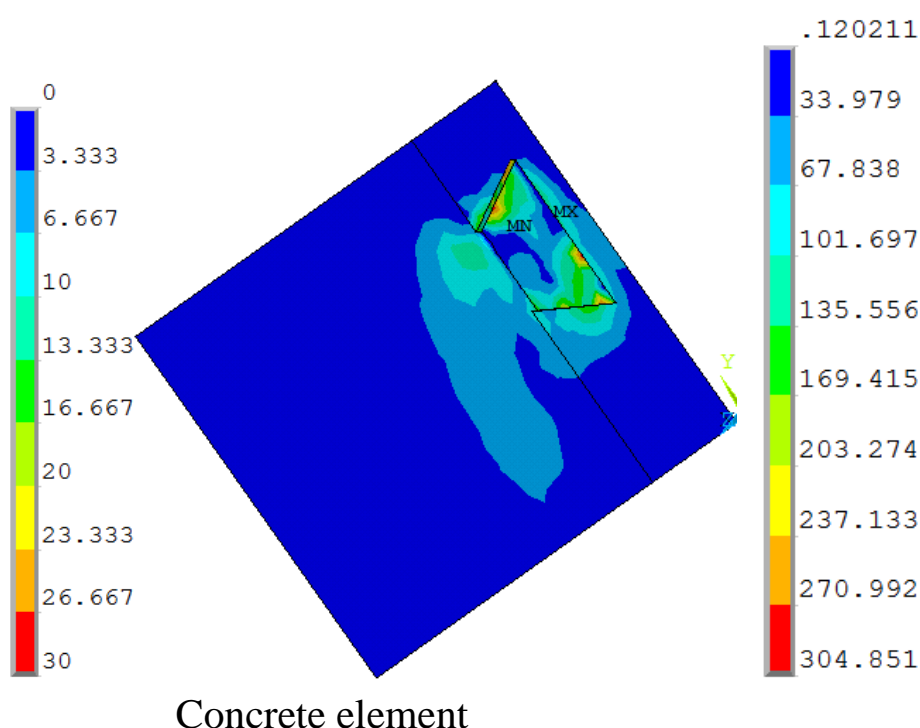

Concrete element

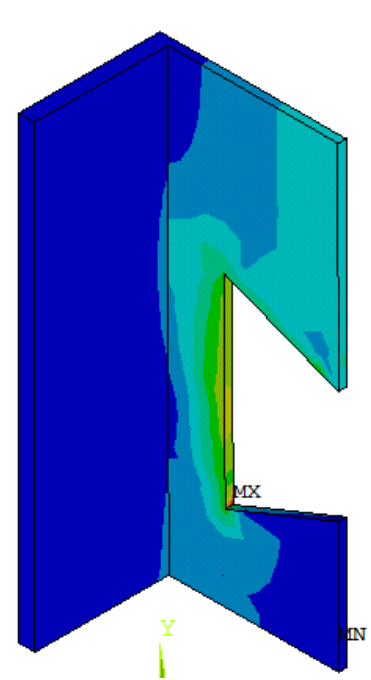

Steel element

(d) Clothoidal opening (CL-Z shape)

Fig. 14: Contour plots of von Mises stress of different shear connection configuration 
Figure 15

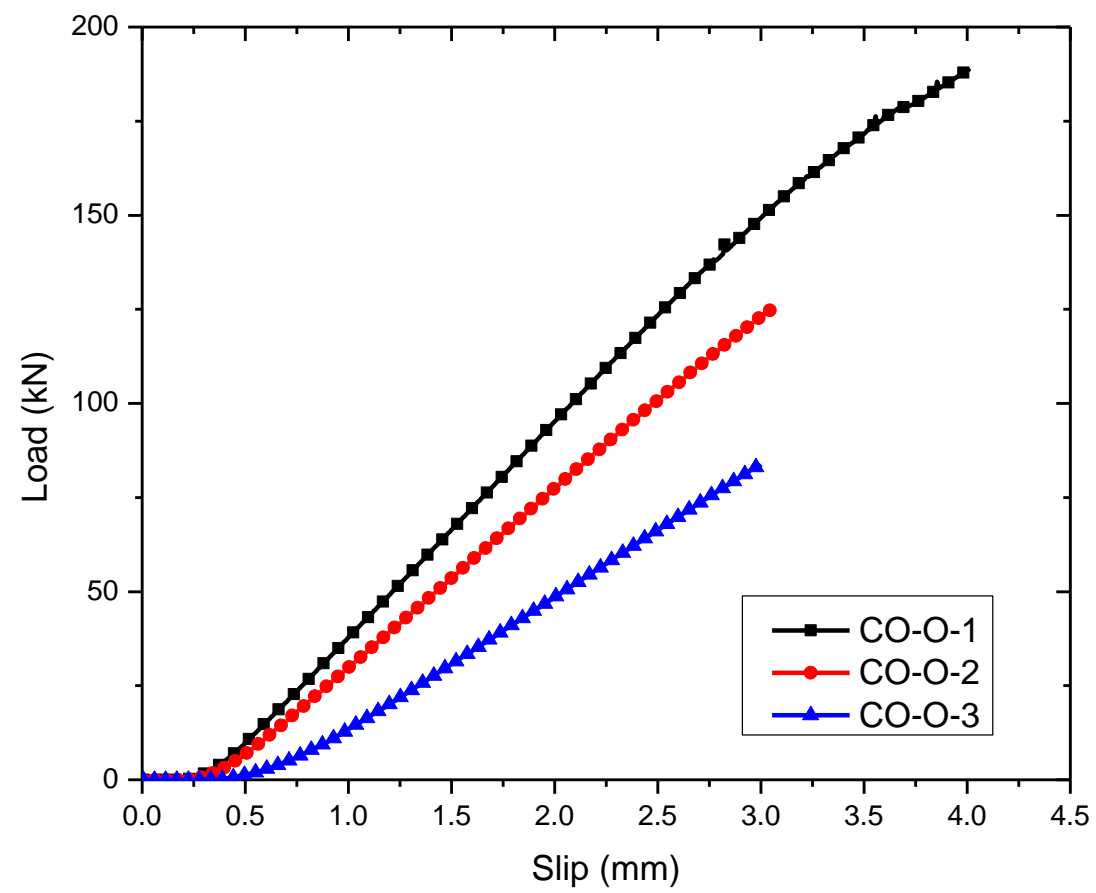

(a) $\mathrm{CO}-\mathrm{O}$ configuration

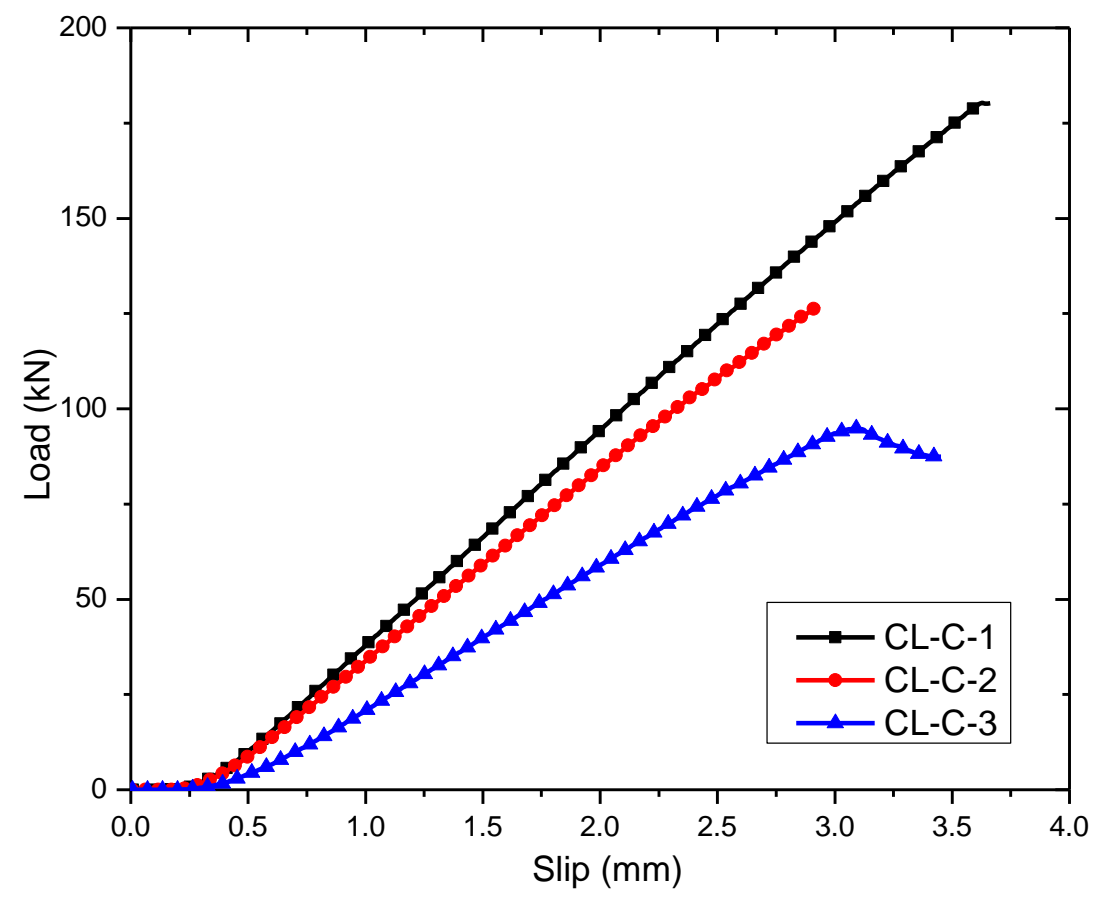

(b) CL-C configuration

Fig. 15: Load-slip curves of shear connections with different shear connection sizes 
Figure 16

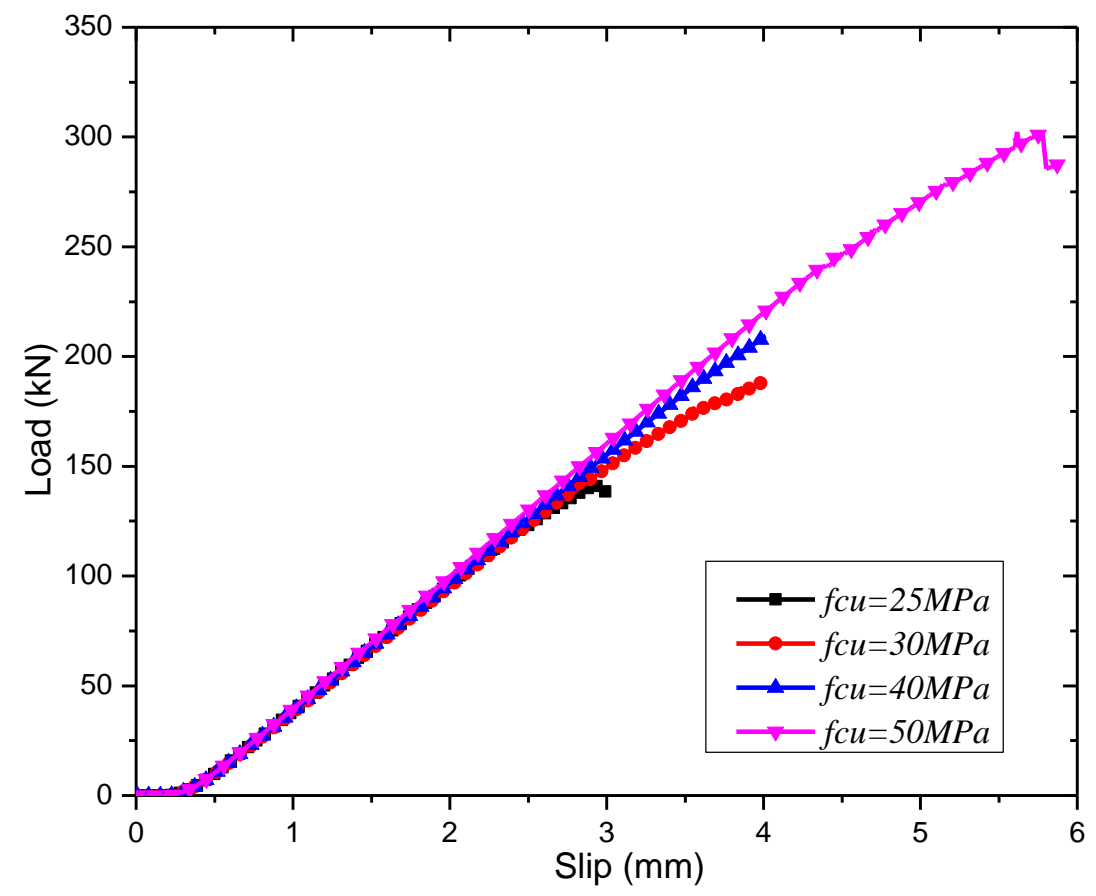

(a) $\mathrm{CO}-\mathrm{O}$ configuration

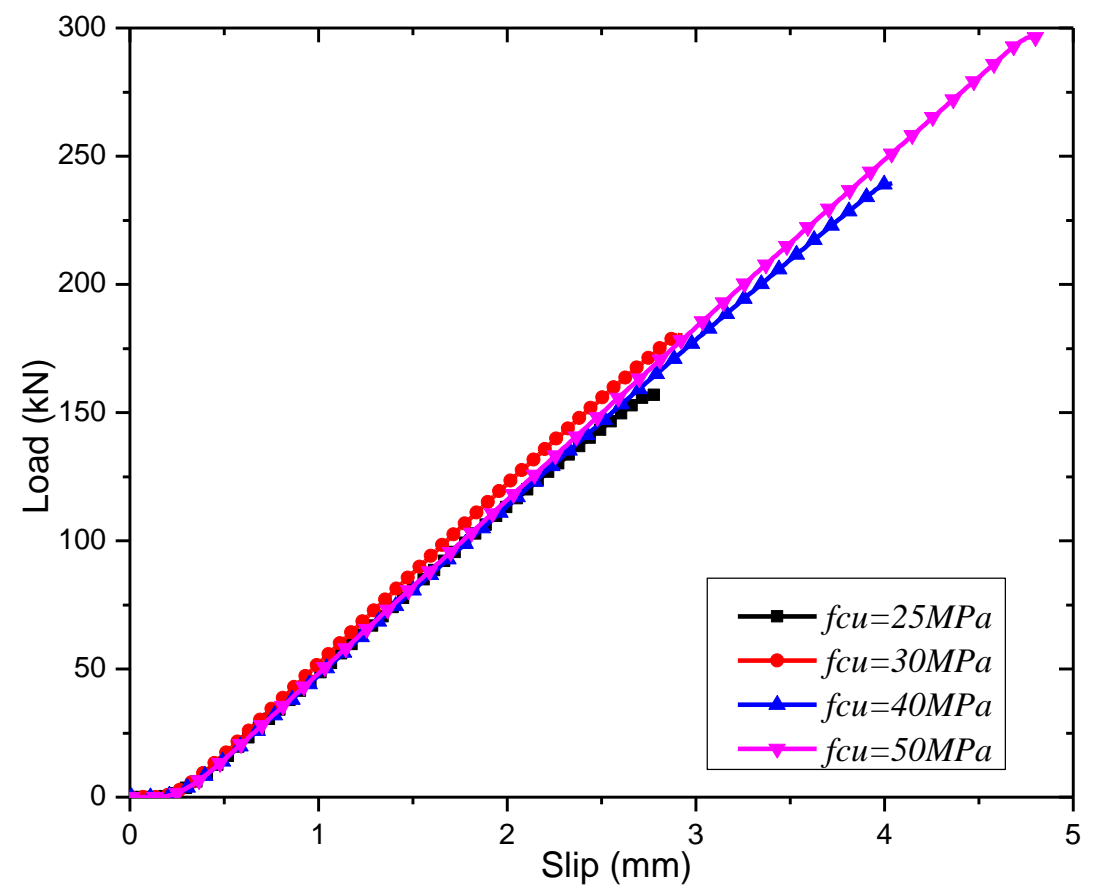

(b) CL-C configuration

Fig. 16: Influence of concrete strength on the load-slip behavior of shear connections 
Figure 17

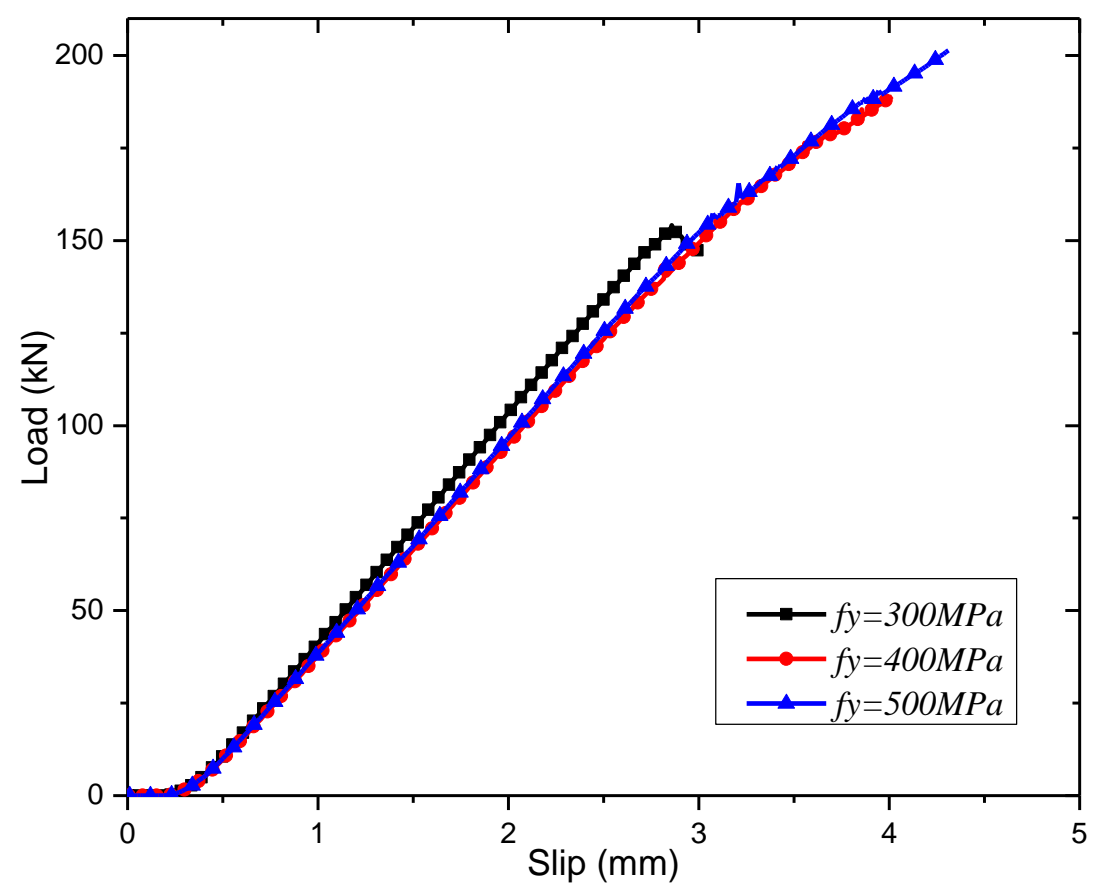

(a) CO-O configuration

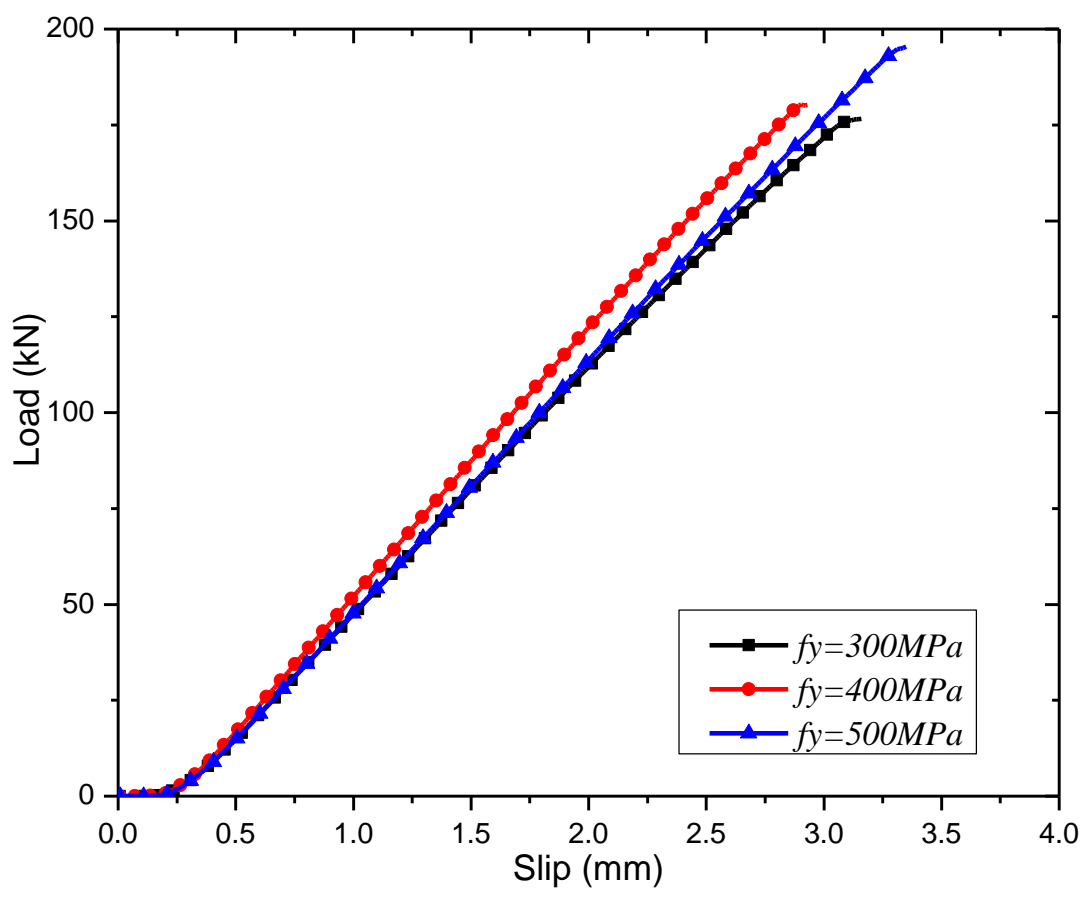

(b) CL-C configuration

Fig. 17 Influence of steel yield strength on the load-slip behavior of shear connections 
Figure 18

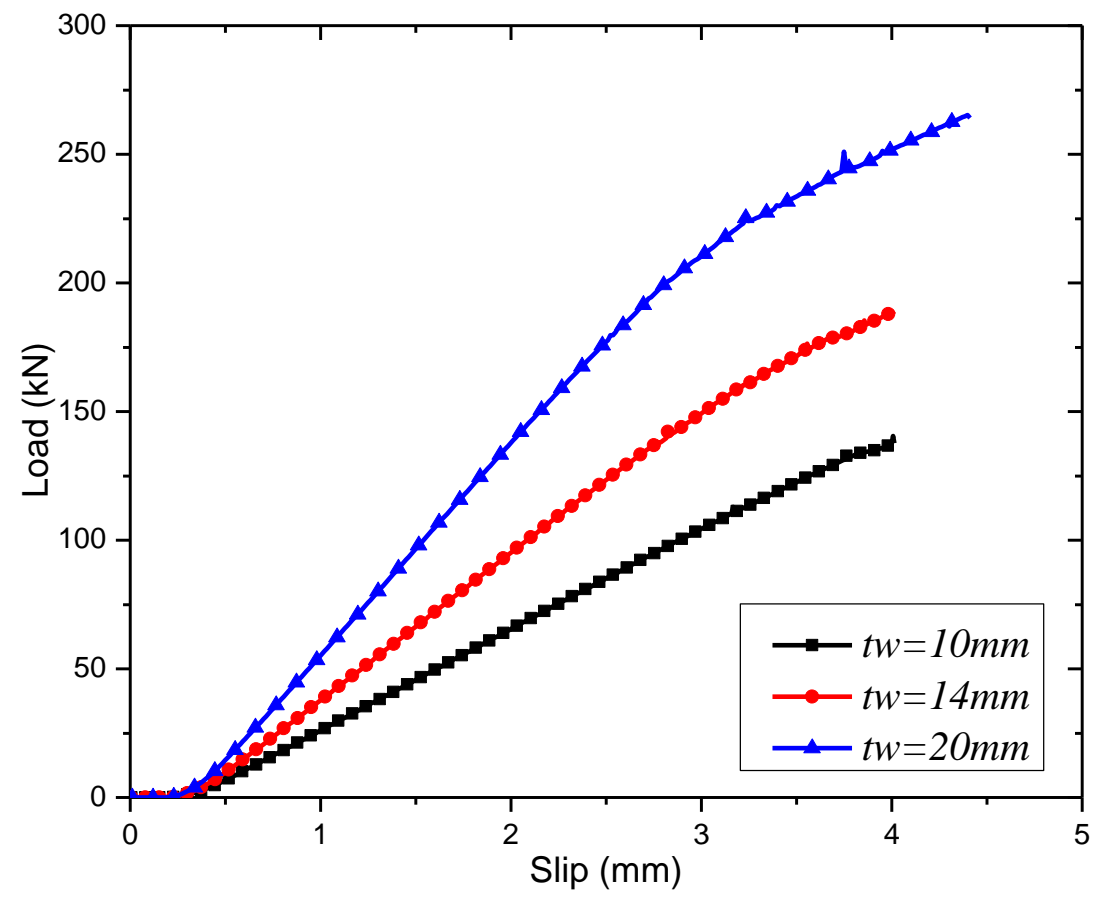

(a) $\mathrm{CO}-\mathrm{O}$ configuration

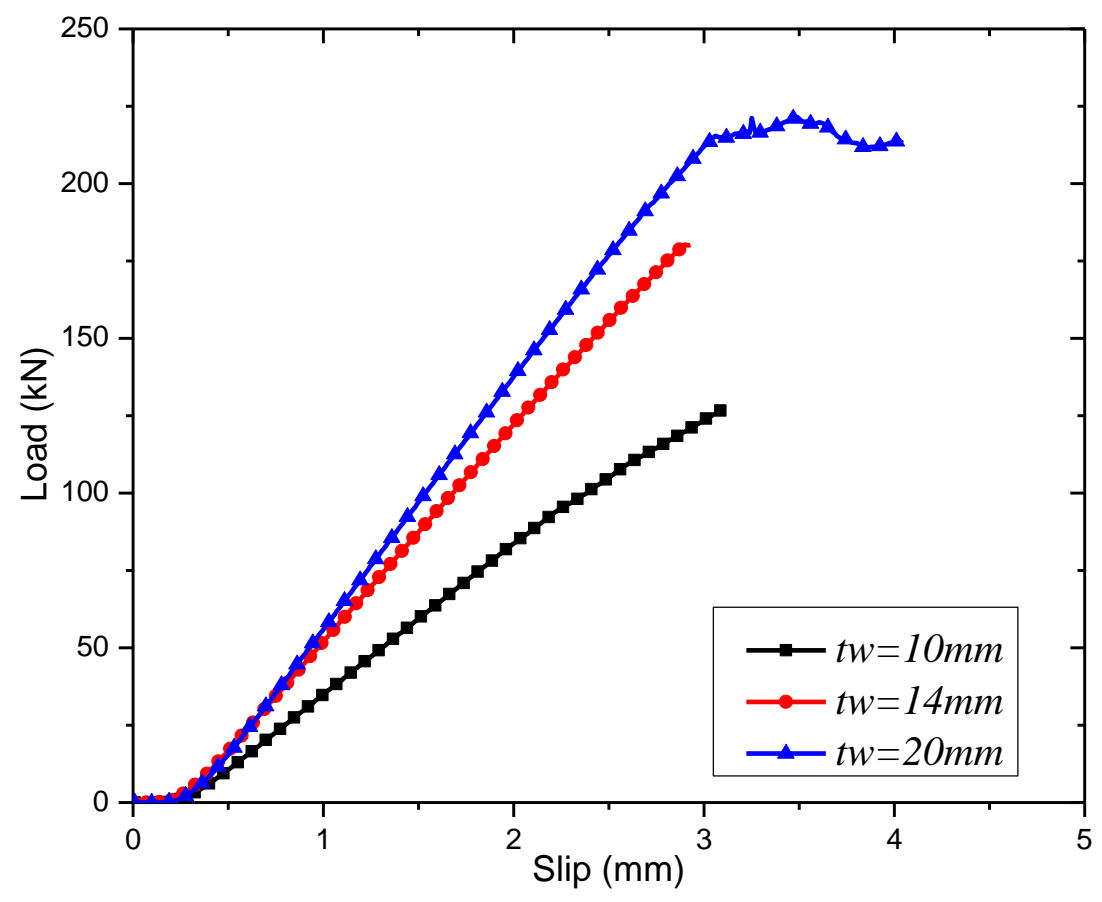

(b) CL-C configuration

Fig. 18: Influence of steel web post thickness on the load-slip behavior 
Figure 19

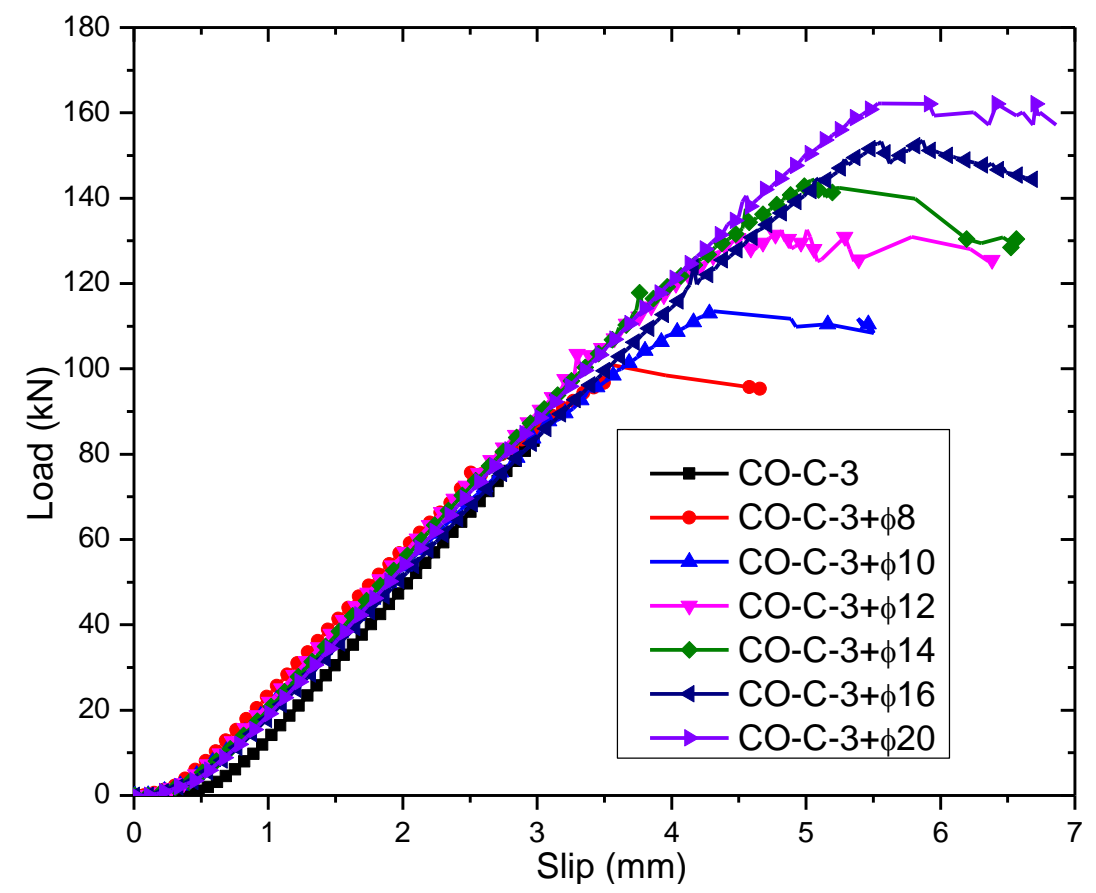

(a) CO-O configuration

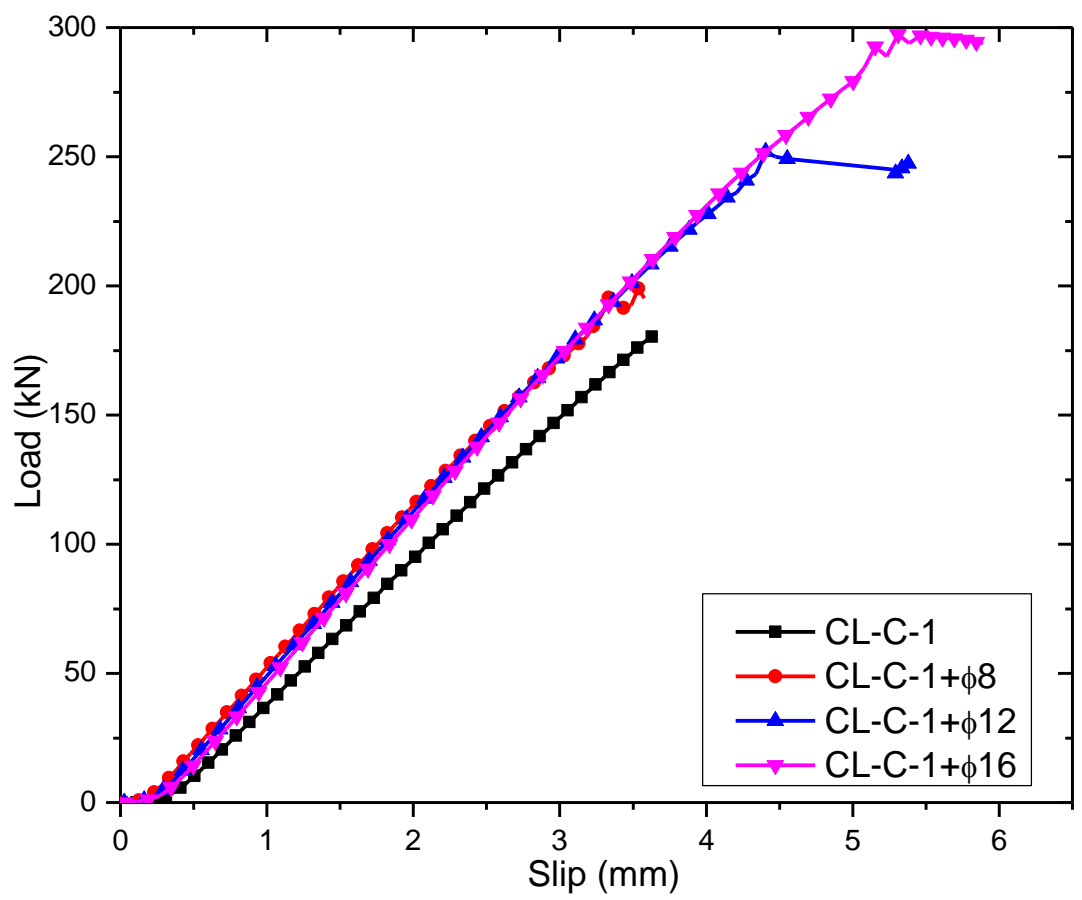

(b) CL-C configuration

Fig. 19: Effects of the reinforced tie-bar element on the load-slip behavior 
Figure 20

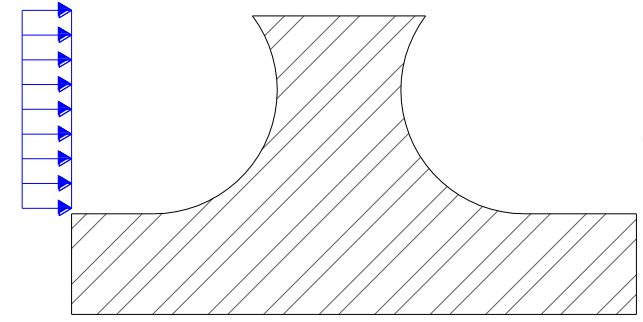

Local composite action

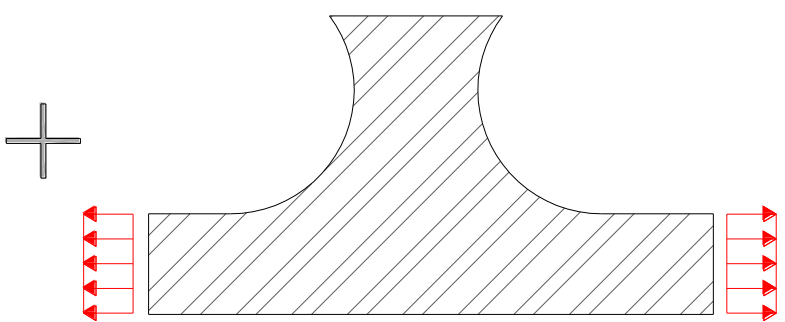

Bending and axial force actions

Fig. 20: Different forces action inducing stress concentration within the steel element 